\title{
Default or Exit? Empirical Study on SMEs in the Japanese Construction Industry
}

\author{
Konno Yukiko
}

March 2015

Graduate School of International Social Sciences

Yokohama National University 


\section{Acknowledgements}

I would like to express my deep and sincere gratitude to my supervisor, Associate Professor Yuki Itoh, Graduate School of International Social Sciences, Yokohama National University. His comments on earlier draft of this dissertation greatly improved the contents.

I am also grateful to the discerning comments of Professor Tohru Inoue and Professor Hiroshi Morita, International Social Sciences, Yokohama National University.

I am very grateful to Professor Junichiro Fukuchi, Department of Economics, Gakushuin University for his advice and support. His understanding, encouraging, and personal guidance have provided a good basis for the present dissertation. I thanks Professor Toshio Hara, International Social Sciences, Yokohama National University for his insightful comments.

\section{Yukiko Konno}

Yokohama National University

March 2015 


\section{Contents}

1 Introduction 1

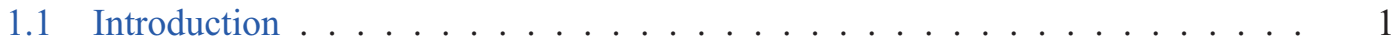

1.2 Organization of this Dissertation . . . . . . . . . . . . . . . 3

1.2.1 Japanese competitive bid entry qualifications: An examination of public

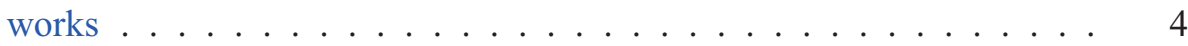

1.2.2 An empirical analysis of the exit of SMEs tendering for public works in the Japanese construction industry . . . . . . . . . . . . . . . . 4

1.2.3 Default or Exit?: Empirical Study on SMEs in the Japanese Construction

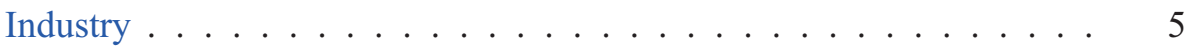

1.2.4 Analysis of Japanese contractor's activity according to panel data . . . 5

2 Japanese competitive bid entry qualifications: An examination of public $\begin{array}{ll}\text { works } & 7\end{array}$

2.1 Competitive Bid Entry Qualifications . . . . . . . . . . . . . . . . . 7

2.2 Keiei Jikou Sinsa $($ Keisin $) \ldots \ldots \ldots$

2.2 .1 Introduction of Keisin $\ldots \ldots \ldots . \ldots . \ldots$

2.2.2 Development of Keisin . . . . . . . . . . . . . . . . . . . . . . . . . . 10

$2.2 .3 \quad$ Keisin Scores . . . . . . . . . . . . . . . . . . . . . . . . . . . . . 10

2.2.4 Period of Validity and Falsified Applications _... . . . . . . . 12 
2.3 Keisin Case Study . . . . . . . . . . . . . . . . . . . . . . . . . . . . . . . . . 12

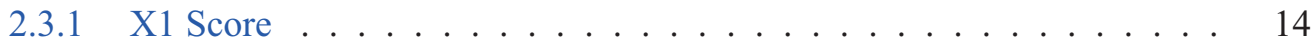

2.3 .2 Z Score . . . . . . . . . . . . . . . . . . . . . . 14

2.3 .3 X2 Score ........................... 15

2.3 .4 Y Score . . . . . . . . . . . . . . . . . . . . . . . 16

2.3 .5 W Score . . . . . . . . . . . . . . . . . . . . . . . 17

2.3.6 Total Score . . . . . . . . . . . . . . . . . . . . . . . . . 18

2.4 Independent Assessment by Orderers . . . . . . . . . . . . . . . . . . . . . 18

2.5 Grading . . . . . . . . . . . . . . . . . . . 22

2.6 Discussion . . . . . . . . . . . . . . . . . . . . 23

$2.6 .1 \quad$ Effectiveness of Keisin . . . . . . . . . . . . . . . . . . . . . 23

2.6 .2 Efficiency of Grading . . . . . . . . . . . . . . 25

3 An empirical analysis of the exit of SMEs tendering for public works in the $\begin{array}{ll}\text { Japanese construction industry } & 26\end{array}$

3.1 Introduction . . . . . . . . . . . . . . . . . . 26

3.2 Literature Review . . . . . . . . . . . . . . . . . . . . . . . . . . . . . 29

3.2.1 Studies of Leaving . . . . . . . . . . . . . . . . . . . . . 29

3.2.2 Studies of the Construction Industry . . . . . . . . . . . . . . 30

3.2.3 Studies of Default Risk of SMEs in Japan . . . . . . . . . . . . . . . 32

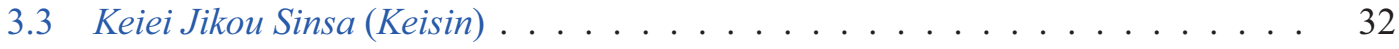

3.4 Empirical Analysis . . . . . . . . . . . . . . . . . . . . . 35

3.4 .1 Overview of the Sample . . . . . . . . . . . . . 35

3.4.2 Variables and the Fundamentals of the Statistics . . . . . . . . . . 36

3.4 .3 Analytical Method . . . . . . . . . . . . . . . . . . . . 38

3.4 .4 Model Selection . . . . . . . . . . . . . . . . . . . 39

3.4.5 Estimated Results and Discussion . . . . . . . . . . . . . . 40

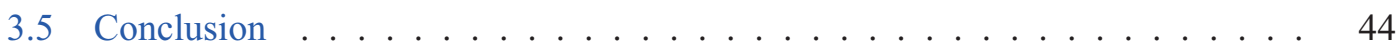


4 Default or Exit?: Empirical Study on SMEs in the Japanese Construction Industry $\quad 47$

4.1 Introduction . . . . . . . . . . . . . . . . . . . 47

4.1.1 Background and Identification of this Study . . . . . . . . . . . . . 47

4.1.2 Definition of Exit and Default and Data Availability of SMEs . . . . . 48

4.1 .3 Originality and Outline of this Study . . . . . . . . . . . . . 51

4.2 Literature Review . . . . . . . . . . . . . . . . . . . . . . 52

4.2 .1 Studies of Default . . . . . . . . . . . . . . . . . 52

4.2 .2 Studies of Leaving . . . . . . . . . . . . . . . . . . . . 54

4.2 .3 Studies of SMEs in Japan _ . . . . . . . . . . . . . . . . 55

4.3 Keisin .............................. 56

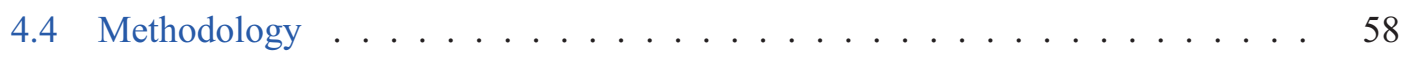

4.4 .1 Analytical Method . . . . . . . . . . . . . . . 58

4.4 .2 Data and Variables ........................ 61

4.4.3 Models with Anticipations . . . . . . . . . . . . . . . 62

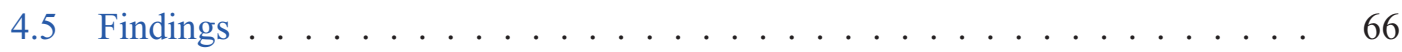

4.6 Conclusion . . . . . . . . . . . . . . . . . . . . . 70

5 Analysis of Japanese contractor's activity according to panel data $\quad 71$

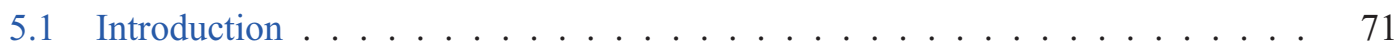

5.2 Literature Review . . . . . . . . . . . . . . . . . . . . . . 72

5.2 .1 Study of Default . . . . . . . . . . . . . . . . . . 73

5.2 .2 Study of Leaving . . . . . . . . . . . . . . . . . 75

5.3 Overview of Keisin . . . . . . . . . . . . . . . . . . . . . . . 76

5.4 Research Method . . . . . . . . . . . . . . . . . . . . . . . . . 77

$5.4 .1 \quad$ Estimation Method . . . . . . . . . . . . . . . . . 77

5.4 .2 Goodness of Fit . . . . . . . . . . . . . . . . . . 79

5.5 Data and Variables . . . . . . . . . . . . . . . . . . . . 79 
5.6 Results and Interpretation $\ldots \ldots \ldots \ldots$. . . . . . . . . . . . 81

5.6 .1 Results . . . . . . . . . . . . . . . . . . . . 81

5.6 .2 Interpretation . . . . . . . . . . . . . . . . 84

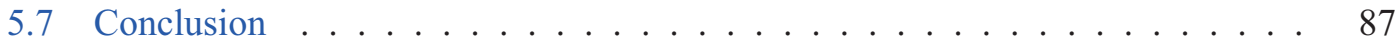

$\begin{array}{lr}\text { Bibliography } & 89\end{array}$ 


\section{Introduction}

\subsection{Introduction}

Since the public work is a kind of public services that are required for maintenance and operation of social capital, the public work is needed to stable supply. Because the prime contractors are selected by the competitive bids, in order to continue the stable supply of the public services, it is important to secure sufficient market participants which participate in the competitive bids.

However, at the present condition in the Japanese construction industry, it is increasing the number of bids that fail to get bidders of the public works. In the engineering works that is ordered by Tokyo Metropolis, the incidence rate of the bids that fail to get bidders exceeds $30 \%$ from December 2013 to January 2014. The incidence rate approaches $40 \%$. In the background, it is the shortfall of human resources by decreasing the number of the contractors. Though the number of contractors is about 601,000 in 1999, it decreases about 470,000 in 2012. As a result, the number of workers is decreasing more than one million.

Especially, it is remarkable that the small scale works whose estimated prices are less than 150 million yen tend to fail to get bidders. In the public works, each contractor are restricted to participate the maximum and minimum of estimated price of bids depending its scale. Therefore, it indicates that the public works that fail to get bidders are often occurred in the bids by the SMEs. Here, if it is able to choice the contractors that continue the business as prime contractors, it gives support to increase the SMEs in construction industry.

The present condition of Japan's construction industry and SMEs is summarised as follows. In line with the definition of SMEs by the Small and Medium-sized Enterprise Basic Act of Japan, 
this study analyses only companies with a capital of 300 million yen (approx. US\$ 3 million) or less. These companies comprise roughly $99 \%$ of Japan's construction industry. The market size of Japan's construction industry is decreasing. However, since the construction industry forms $8 \%$ of the total number of persons engaged, the construction industry is an important industry that still contributes to the stability of employment.

As for the actual structure in the construction industry, the number of contractors that contract subcontracted construction projects account for $79.2 \%$ of the whole, and the number of contractors where subcontract revenue occupies $50 \%$ or more account for $49.6 \%$. Furthermore, the contractors where dealings with one specific prime contractor occurs $50 \%$ or more account for $31.7 \%$ among contractors that contract subcontracted construction projects, and the exclusive ratio tends to increase as the capital decreases.

Overall, these statistics reflect the increasing dependence on subcontractors and the stratification of the subcontract structure by prime contractors. Moreover, the public works ordering ratio, which accounts for the construction revenue of public works among the entire construction industry in Japan, is $30.4 \%$. When classifying companies with regard to capital, the ratio of the companies with capital of more than 30 million yen but less than 50 million yen is $40.8 \%$ (highest in the class) and of those with capital of more than 50 million yen but less than 100 million yen is $31.5 \%$ (second highest in the class). In contrast, the ratio of the companies with capital of less than five million yen is $20.3 \%$ (lowest in the class).

This study aims to focus on contractors that contract public works construction projects. Preventing several major contractors from controlling the bidding of public works projects can ensure that a certain number of other participants are involved. Therefore, analysing the factors that affect the defaults or exits of SMEs can effectively contribute to the stable supply of public services and the fair competition of bids.

In Japan, it is not enough to develop the database that includes financial information of SMEs. There is a few database of SMEs. However, they are almost questionnaire data and they may lack accuracy. Therefore, there are few studies for the default and the exit from the industry 
using microdata of SMEs. Moreover, the most of literatures are studies in related areas focus only on default and bankruptcy or leave an industry containing default. However, the default contractors are very different from exit contractors in terms of their corporate activity. Thereby, it is necessary to distinguish between defaults and exits for analysis.

This study analyzes the credit risk and exits risk of SMEs in the Japanese construction industry using construction company evaluation (Keiei Jikou Sinsa or Keisin in Japanese) data for bid entry qualifications of public works. Using national technological, management, and social standards, Keisin evaluates the responsibility of each company that contracts public works projects according to Japan's Construction Business Act. In order to bid for public works projects, the prime contractors must be evaluated by Keisin. Furthermore, since Keisin is provided penalty for false application, Keisin data is high reliable data that has enough information for analysis of risk management.

Based on the Keisin applications, this study defines the default, exit and continuation of public works for contractors, as follows. Default refers to contractors that applied for Keisin in a certain fiscal year, but not in the following year, and contractors that were either forced to discontinue their business or went bankrupt. Exit refers to contractors that applied for Keisin in a certain fiscal year, but not in the following year, and contractors that are not cases of default. Continuation refers to contractors that applied for Keisin in a certain fiscal year as well as in the following year and contractors that are not cases of default.

\subsection{Organization of this Dissertation}

This dissertation comprises largely for studies: Japanese competitive bid entry qualifications: An examination of public works; An empirical analysis of the exit of SMEs tendering for public works in the Japanese construction industry; Default or Exit?: Empirical Study on SMEs in the Japanese Construction Industry; Analysis of Japanese contractor's activity according to panel data. 


\subsubsection{Japanese competitive bid entry qualifications: An examination of public works}

Chapter 2, "Japanese competitive bid entry qualifications: An examination of public works", summarizes the independent competitive bid entry qualifications examination of public works in Japan, and considers its significance. Each orderer of public works examines the contractors who will participate in competitive bidding. Those contractors not disqualified must be graded on the basis of the objective examination score and an independent assessment by the orderer. Firms may be disqualified on the grounds of, for example, bankruptcy or false qualifications. The Japanese grading system in public bids ensures competitive bidding among firms with similar scale and capability. If orderers order only large scale construction, only large contractors with higher scores can obtain the construction contracts. However, in split orders, SMEs with lower scores have the opportunity to obtain construction contracts. Moreover, as the bid entry qualifications and bids themselve are conducted for every industry class, contractors of all industries can also win the construction contract as the prime contractor. Therefore, the Japanese grading system in public bids provides opportunities for SMEs in every industry class to obtain constructions contracts as prime contractors.

\subsubsection{An empirical analysis of the exit of SMEs tendering for public works in the Japanese construction industry}

Chapter 3, "An empirical analysis of the exit of SMEs tendering for public works in the Japanese construction industry", empirically analyzes the factors that affect exits of SMEs in the Japanese construction industry. To contract public works projects, prime contractors must undergo Keisin that is bid entry qualifications of public works. Therefore, Chapter 3 regard the contractors which they did not apply for Keisin as having exited from public works, because they cannot be principal contractors of public works. Based on the Keisin applications, Chapter 3 empirically analyzes their exits using the binary logit model. From these results, contractors with low capital and score of Keisin, and those that have been operating for fewer years tend to exit. Because of 
this, since total score is high, the contractors that get the opportunity to be able to participate in the bids of large scale construction and contract the large scale construction, continue the public-works. On the other hand, younger contractors with low capital tend not to participate in bids for public works and prefer to serve as subcontractors for public works or in the private sector.

\subsubsection{Default or Exit?: Empirical Study on SMEs in the Japanese Construction Industry}

Chapter 4, "Default or Exit?: Empirical Study on SMEs in the Japanese Construction Industry", empirically analyses the factors that affect the defaults and exits of SMEs in the Japanese construction industry by using the multinomial logit model. Consequently, Chapter 4 shows that the characteristics of defaulting and exiting contractors are different. In the case of financial indicators, debt turnover period affects defaults. When contractors are not able to pay their debts, a default is considered to have occurred. Therefore financial debt ratios such as debt turnover period are relevant to defaults. In contract, financial debt ratios do not have a significant effect on exiting, and contractors with low capital and those that have been operating for fewer years tend to exit. Because of this, Chapter 4 considers that younger contractors with low capital tend not to participate in bids for public works and prefer to serve as subcontractors for public works or in the private sector. In addition, as the profit ratio became small, it is easy to exit and default. Also, it is suggested that contractors with high profit ratios are able to continue operating without having to default or exit.

\subsubsection{Analysis of Japanese contractor's activity according to panel data}

Chapter 5, "Analysis of Japanese contractor's activity according to panel data", examines what factors affect defaults and exits of prime contractors of public works on SMEs in the Japanese construction industry, and determines how changes in the characteristic of contractors affect default and exit by analyzing data for several years as panel data, using the panel binary logit 
random effect model. Chapter 5 can thereby analyze the factors that affect defaults and exits for each explanatory variable while considering heterogeneity among contractors. The result shows financial indicators, non-financial indicators, and Keisin scores significantly affect default and exit. Especially, the result that non-financial performance such as taking out insurances (retirement allowances or company pension and non-statutory worker's compensation system) explains the differences between defaulting and exiting contractors is novel. Although the Keisin data are used only to determine whether contractors are qualified to enter bids for public works, it is possible to apply them to the attribution analysis of the default and exit of contractors. 


\section{Japanese competitive bid entry qualifications: An examination of public works}

\subsection{Competitive Bid Entry Qualifications}

In Japan, contractors who wish to undertake public works must take an independent bid entry qualification examination for grading. No foreign countries have a similar system, and few academic studies have addressed this system. Therefore, the present study explains the Japanese public works competitive bid entry qualification examination of public work.

Contractors with capital of less than 300 million yen or one-person businesses - that is, small and medium-sized businesses (SMEs) — comprise about 99\% of Japan's construction industry. Although market size is decreasing overall, construction industry workers comprise approximately $8 \%$ of all workers in Japan. This industry plays an important role in not only supplying social capital but also contributing to employment stability (for details, see Japan Federation of Construction Contractors (2012)).

Construction projects are classified into public works and private projects. The acceptances of orders and the executions of works differ as per of project types. In private projects, the orderer arbitrarily chooses the contractor, except for large-scale construction projects. Public works projects determine the contractor principally by competitive bidding, and the successful bidder obtains the contract. In Japan, contractors who wish to undertake public works must be scored 
by a nationally standardised objective examination across Japan. The objective examination is called Keiei Jikou Sinsa or Keisin in Japanese (henceforth, referred to as Keisin) and is conducted by the Ministry of Land, Infrastructure, Transport and Tourism (MLIT) or the prefecture governor in accordance with Japan's Construction Business Act.

Each orderer of public works examines the contractors who will participate in competitive bidding. Those contractors not disqualified must be graded on the basis of the objective examination score and an independent assessment by the orderer. Firms may be disqualified on the grounds of, for example, bankruptcy or false qualifications.

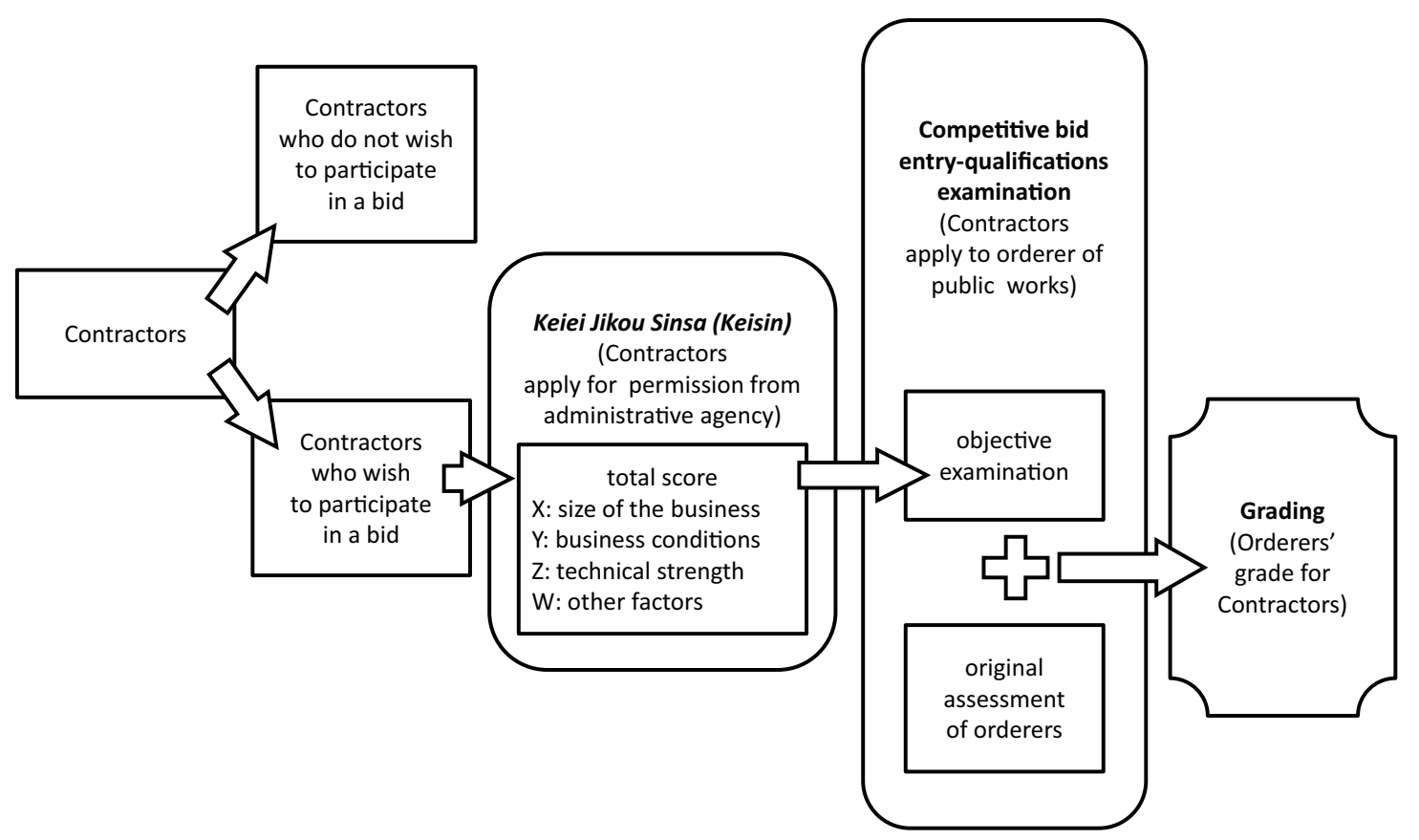

Figure 2.1: Flow of Competitive Bid Entry Qualifications

The successful bidder decision system of competitive bidding for public works in Japan is classified into the lowest-price bidding system (LBS) and the general evaluation system (GES).

The structure of successful bidding projects in the LBS is as follows. Contractors who make the grade for the order offer bids. The contractor who offers a bid below the estimated price, which is a secret maximum price for every project, and offers the lowest price among the of- 
fers, generally obtains the contract. To prevent dumping, low-tender offers are investigated to determine whether the bid price is unreasonable and risks failing to fulfil the contract in some cases.

In contrast to LBS, which focuses only on the bidding price, successful bidders are determined in GES by comprehensively evaluating the bidding prices and other elements (such as quality and technical proposal).

\subsection{Keiei Jikou Sinsa (Keisin)}

As noted in Section 2.1, Keisin is the nationwide standardised objective examination for competitive bid entry qualification. Roughly $30 \%$ of the contractors in Japan have undertaken Keisin, which will be explained in detail in the following subsections.

\subsubsection{Introduction of Keisin}

This subsection reviews the history of Keisin. For details, see Takahashi (2001) and Yoshimori (2006).

After World War II, the market was flooded with inexperienced contractors who did not have required technology. To preserve suitable construction quality and the healthy development of the construction industry, the Construction Industry Law was enacted in 1949. However, since the authorisation of contractors occurred via the registration system, by completing the registration, companies could become authorised contractors. Therefore, many contractors had problems in construction capability, financial condition and credit. This situation motivated the evaluation of construction capability (Kouji Sekou Nouryoku Sinsa), which is the past tense of Keisin, and which was institutionalised in 1950; then the evaluation of contractors (Keiei Jikou Sinsa) was changed in 1973. Keisin became the system which focuses on comprehensive contractor capability, including not only construction capability but also technical capabilities and financial condition. 


\subsubsection{Development of Keisin}

Keisin itself is frequently revised according to the economic environment and the status of the construction industry. In recent years, revision has focused on two issues: the deterioration of the quality of public works projects from intense bid competition and the strengthening of punishment for dishonest behaviour such as collusive bidding at the urging of government agencies. Thus, to perform corporate evaluation for public works projects properly, the Central Council on Construction Contracting Business continually revises score items or the standard on the basis of socioeconomic conditions. In 2008, they added items strengthening preventive measures for falsified applications, disaster prevention and corporate pensions.

\subsubsection{Keisin Scores}

This subsection explains the method of scoring Keisin. For details, see Kanto Regional Development Bureau, Ministry of Land, Infrastructure, Transport and Tourism (2012). By the national standard's technological, management and social factors, Keisin evaluates the capability of construction firms which contract for public works projects.

As shown in Table 2.1, the items consist of (1) the size of the business (X1 score and X2 score), (2) business conditions (Y score), (3) technical strength (Z score) and (4) other matters (W score). They are evaluated with scoring, and the total score is the weighted sum of the scores Equation (2.1):

$$
\text { total score }=0.25 \times \mathrm{X} 1+0.15 \times \mathrm{X} 2+0.2 \times \mathrm{Y}+0.25 \times \mathrm{Z}+0.15 \times \mathrm{W} \text {. }
$$

The $\mathrm{X} 1$ and $\mathrm{X} 2$ scores represent business size. The $\mathrm{X} 1$ score is based on the average annual construction revenue in the classified industry for either the last two or three years. The average can be computed arbitrarily for either the latest two or three years. The X2 score comprises two items: shareholder equity and average earnings. The Y score is the index of business conditions 
Table 2.1: Keisin Items

\begin{tabular}{|c|c|c|}
\hline Item & Evaluation item & Score width \\
\hline $\mathrm{X} 1$ & Construction revenue (industry-classified) & $390-2268$ \\
\hline $\mathrm{X} 2$ & $\begin{array}{l}\text { Shareholder equity } \\
\text { Average earnings }\end{array}$ & $454-2280$ \\
\hline Y & $\begin{array}{l}\text { Net paying interest / revenue } \\
\text { Debt turnover period } \\
\text { Ordinary income ratio } \\
\text { Gross profit / total capital } \\
\text { Net worth to fixed assets ratio } \\
\text { Capital-to-asset ratio } \\
\text { Cash flow from operations (absolute cost) } \\
\text { Earned surplus (absolute cost) }\end{array}$ & $0-1595$ \\
\hline $\mathrm{Z}$ & $\begin{array}{l}\text { Number of technical staff (industry-classified) } \\
\text { Prime construction revenue (industry-classified) }\end{array}$ & $450-2366$ \\
\hline $\mathrm{W}$ & $\begin{array}{l}\text { Labour welfare } \\
\text { Continuation of operating of the construction industry } \\
\text { Contribution to a disaster-prevention activity } \\
\text { Compliance } \\
\text { Accounting of the construction industry } \\
\text { Research and development } \\
\text { Possession of construction machinery } \\
\text { International organisation for standardisation }\end{array}$ & $0-1750$ \\
\hline
\end{tabular}


and comprises financial performance indicators; it also measures financial soundness. The $\mathrm{Z}$ score indicates construction capability and technical strength. As the $\mathrm{Z}$ score is computed using the prime construction revenue and the number of technical staff for the industry, it is generally proportional to the business size. The $\mathrm{W}$ score is the evaluation of social value, such as corporate social responsibility and contribution.

\subsubsection{Period of Validity and Falsified Applications}

Keisin data are publicly available on the Internet. The period of validity for Keisin is one year and seven months from the settling day immediately preceding examination of applications.

Based on Article 27 of the Construction Law, contractors with objections to the Keisin results may apply for re-examination to the MLIT or the prefecture governor who made the examination. Penal regulations, such as imprisonment or fines, are in place to deter falsified Keisin applications. Penalties are in place for false statements on applications, failure to submit materials and the submission of false materials. In some cases, contractors may be given directions or have their business interrupted (administrative disposition) by the relevant administrative agency. Furthermore, when a punishment is imposed, Keisin permission is revoked, and the contractor is prohibited from obtaining Keisin permission for five years.

Moreover, because Keisin is continually revised according to current trends and penal regulations have been established for falsified applications, it is reliable.

\subsection{Keisin Case Study}

To explain the calculation of Keisin clearly, this section uses a virtual contractor. Keisin scores of the virtual company comprise four tables: Table 2.2 on the $\mathrm{X} 1, \mathrm{Z}$ and total scores; Table 2.3 on the $\mathrm{X} 2$ score; Table 2.5 on the $\mathrm{Y}$ score and Table 2.6 on the $\mathrm{W}$ score. 


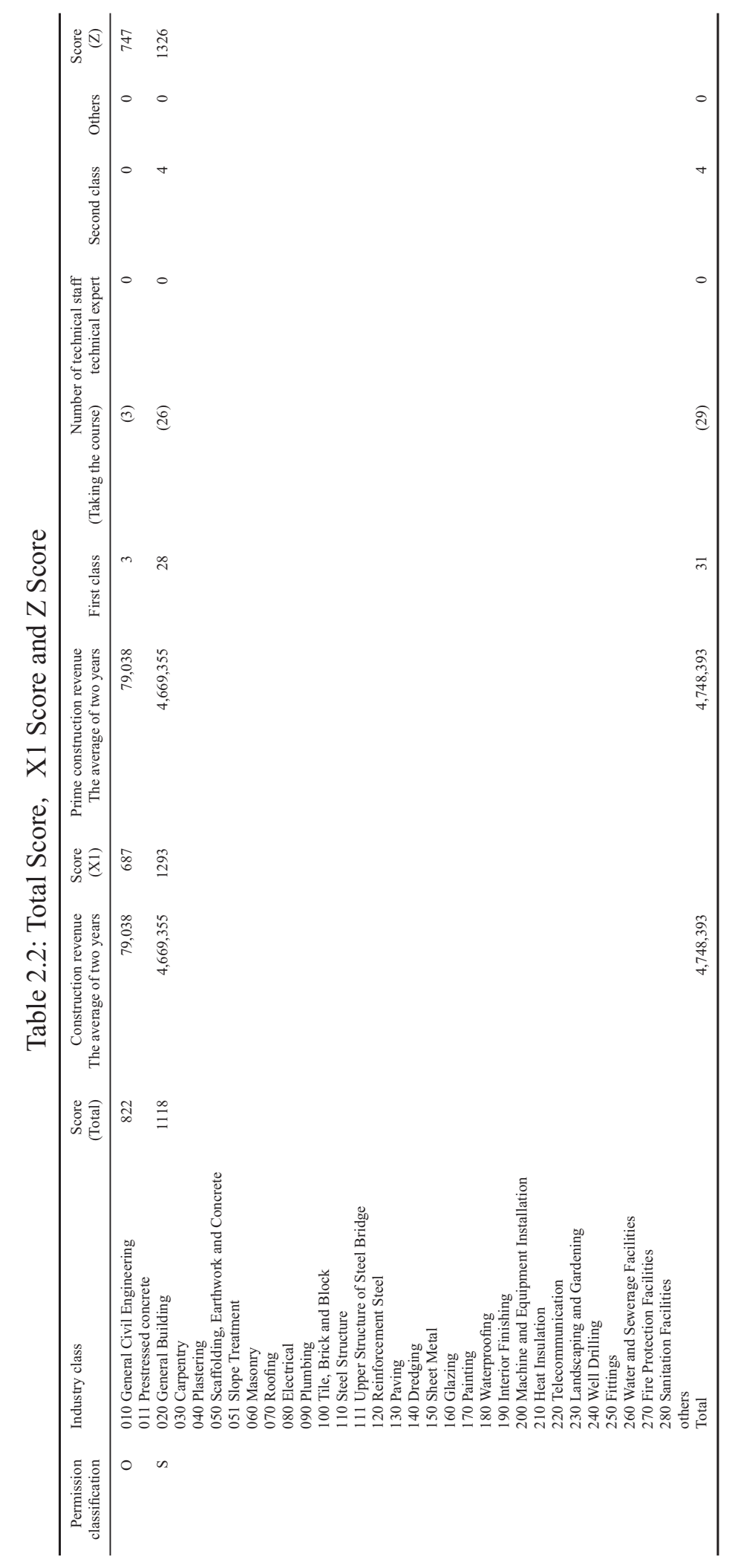


The contractor's construction license classification each industry class is represented by the symbols ' $\mathrm{O}$ ' or ' $\mathrm{S}$ ' in Table 2.2. ' $\mathrm{O}$ ' indicates the Ordinary Construction License and ' $\mathrm{S}$ ' represents the Special Construction License. The difference between the Ordinary Construction License and Special Construction License is the payment amount which the prime contractor can offer subcontractors. When a prime contractor offers 30 million yen or more (for the general building industry class, 45 million yen or more) in payments to subcontractors per construction, the prime contractor is required to have a Special Construction License. For the virtual company, the construction license of general civil engineering is an Ordinary Construction License and that of general building is a Special Construction License.

\subsubsection{X1 Score}

The construction revenue indicates construction revenue for every industry class. The X1 score is calculated according a certain function, which is rather complicated, and includes the average annual construction revenue for each industry class for either the last two or three years. The average can be computed arbitrarily for the latest two or three years. However, contractors should unify them to the same standard in all industry classes. For the virtual company in Table 2.2, the construction revenue of general civil engineering is 79,038,000 yen and that of general building is 4,669,355,000 yen for the two-year average. The X1 score of general civil engineering is 687 points and that of general building is 1293 points.

\subsubsection{Z Score}

The prime construction revenue indicates construction revenue which orderers offer contractors directly. The $\mathrm{Z}$ score is calculated using prime construction revenue and number of technical staff for a certain function. The average of the prime construction revenue can be computed arbitrarily for the latest two years or three years. However, contractors should unify them to the same standard in all industry classes. For the virtual company in Table 2.2, the prime construction revenue for general civil engineering is 79,038,000 yen and that of general building 
is $4,669,355,000$ yen for the two-year average. As the prime construction revenue is the same as construction revenue, the contractor is contracted as prime contractor for the all construction projects.

For number of technical staff in Table 2.2, each 'first class', 'technical expert', and 'second class' indicate the number of technical staff with each qualification and 'others' represents the number of engineers with experience in the actual business but without qualification for every industrial classification. 'Taking the course' indicates number of the first class technical staff who took the course. For the virtual company in Table 2.2, the number of first class technical staff is three (who took the course) in general civil engineering. The number of first class technical staff is 28 (including 26 who took the course) and that of second class technical staff is four in general building.

The $\mathrm{Z}$ score each industry class is calculated using prime construction revenue and number of technical staff: 747 points for general civil engineering and 1326 points for general building. The total score is the weighted sum of the scores, which this study explains at the end of this section.

\subsubsection{X2 Score}

By scoring the amount of shareholder equity and that of the average earnings according a certain function, the $\mathrm{X} 2$ score is derived by mean of these scores.

For the virtual company in Table 2.3, the amount of shareholder equity is 2,181,931,000 yen, and the score is 1015. The amount of average earnings is 47,069,000 yen, and the score is 690 . The company's X2 score is 852 points, which is the mean of 1015 and 690.

Table 2.3: X2 Score

\begin{tabular}{crr}
\hline Shareholder equity and average earnings & Numerical value (one thousand yen) & Score \\
\hline Shareholder equity & $2,181,931$ & 1015 \\
Average earnings & 47,069 & 690 \\
Score (X2) & & 852 \\
\hline
\end{tabular}




\subsubsection{Y Score}

The Y score was designed by the Central Council on Construction Contracting Business, which revises Keisin, as the index of the default probability of construction company based on its financial performance indicators. Refer to Central Council on Construction Contracting (2007) for details. Table 2.4 reports the indexes comprising the $\mathrm{Y}$ score, which include four aspects: power of resistance to debt, profitability/efficiency, financial soundness, and absolute ability.

(a) Power of resistance to debt. These indexes are drawn from debt bankruptcy discriminant analysis. Given that the shortage of repayment capacity to excessive debt causes bankruptcy, the indexes evaluate contractors by their power of resistance to debt.

(b) Profitability/efficiency. These indexes indicate the efficiency of assets and capital, as well as profitability. The gross margin shows profitability and efficiency in a competitive market, and ordinary profit indicates the routine ability to acquire a benefit.

(c) Financial soundness. These indexes indicate the soundness of fixed assets as well as overall soundness.

(d) Absolute ability. These are quantitative indexes. They indicate the accumulation of the realistic cash flow and profits.

Table 2.4: Four Standpoint of Y Score

\begin{tabular}{llrrrr}
\hline Standpoint & Index & Symbol & Max & Min & Unit \\
\hline \multirow{2}{*}{ Power of resistance to debt } & Net paying interest / revenue & Y1 & 5.1 & -0.3 & percentage \\
& Debt turnover period & Y2 & 18 & 0.9 & month \\
\multirow{2}{*}{ Profitability/Efficiency } & Ordinary income ratio & Y3 & 63.6 & 6.5 & percentage \\
& Gross profit / total capital & Y4 & 5.1 & -8.5 & percentage \\
\multirow{3}{*}{ Financial soundness } & Net worth to fixed assets ratio & Y5 & 350 & -76.5 & percentage \\
& Capital-to-asset ratio & Y6 & 68.5 & -68.6 & percentage \\
Absolute ability & Cash flow from operations & Y7 & 68.5 & -68.6 & 100 million yen \\
& Earned surplus & Y8 & 100 & -3 & 100 million yen \\
\hline
\end{tabular}

Table 2.4 lists the items in each factor. Each item has a certain maximum and minimum value. The Y score is calculated using Equation (2.2), where Y1-Y8 are the symbols shown in 
Table 2.4.

Y Score $=167.3 \times \mathrm{A}+583$, where

$$
\begin{aligned}
\mathrm{A}= & -0.4650 \times \mathrm{Y} 1-0.0508 \times \mathrm{Y} 2+0.0264 \times \mathrm{Y} 3+0.0277 \times \mathrm{Y} 4 \\
& +0.0011 \times \mathrm{Y} 5+0.0089 \times \mathrm{Y} 6+0.0818 \times \mathrm{Y} 7+0.0172 \times \mathrm{Y} 8+0.1906
\end{aligned}
$$

Table 2.5 reports the virtual company's Y score. Net paying interest / revenue is $-0.15 \%$, the debt turnover period is 2.497 months, the gross profit / total capital is $24.244 \%$, the ordinary income ratio is $5.1 \%$, the net worth to fixed assets ratio is $256.624 \%$, the capital-to-asset ratio is $68.5 \%$, cash flow from operations is $33,900,000$ yen and earned surplus is $381,800,000$ yen. Thereby, the Y score is 901 points.

Table 2.5: Y Score

\begin{tabular}{crcr}
\hline Business conditions & Numerical value & Business conditions & Numerical value \\
\hline Net paying interest / revenue & -0.15 & Net worth to fixed assets ratio & 256.624 \\
Debt turnover period & 2.497 & Capital-to-asset ratio & 68.5 \\
Gross profit / total capital & 24.244 & Cash flow from operations & 0.339 \\
Ordinary income ratio & 5.1 & Earned surplus & 3.818 \\
& & Score (Y) & 901 \\
\hline
\end{tabular}

\subsubsection{W Score}

The W score is the evaluation of social value, such as corporate social responsibility and contribution. The W score, which is rather complicated, is calculated using the items listed in Table 2.6. These items include labour welfare (existence of subscription to each insurance and that of introduction of systems), the continuation of operating in the construction industry (operating years, existence of application of the Civil Rehabilitation Act or Corporate Reorganization Act) and contribution to a disaster-prevention activity (conclusion of a disaster prevention agreement). Moreover, points are deducted if contractors have had business suspended or in- 
structions imposed as the condition of compliance. For other factors, the $\mathrm{W}$ score evaluates the accounting in the construction industry, research and development and possession of construction machinery. In 2011, contractors' status of compliance with the international organisation for standardisation, which is ISO 9001 and ISO 14001 registration, was added. As contractors are required to obtain the certification for each item, the $\mathrm{W}$ score is objective, with no room for discretion.

Regarding the virtual company in Table 2.6, as the contractor takes out almost all insurances, the labour welfare situation is good. The contractor has 57 years of operation with continuous and corporate activity. However, the contractor has neither invested in research and development, nor owns construction machinery, nor registered for ISO. Therefore, the W score is 1035 points.

\subsubsection{Total Score}

The total score is calculated from the X1, X2, Y, Z and W scores per Equation (2.1). From the virtual company in Table 2.2, the total score of general civil engineering is 822 points and that of general building is 1118 points.

\subsection{Independent Assessment by Orderers}

Among the competitive bid entry qualifications, the orderer's independent assessment differs by orderer. Therefore, it is also called a subjective examination. However, the standard of the orderer's independent assessment is mainly the records and performance ratings of the orderer's past construction contractors. Moreover, some orderers evaluate contractors' registration for ISO, employment of disabled persons and the existence of a disaster prevention agreement.

For the case study, this section explains the scoring by the independent valuation for construction projects directly controlled by the MLIT. According to Equation (2.3) and Table 2.7, contractors are evaluated by the records of construction projects directly controlled by the MLIT, the records of construction projects of the GES and records of construction projects by local 
Table 2.6: W Score

\begin{tabular}{|c|c|c|}
\hline Other matters & Situation & Score \\
\hline Taking out unemployment insurance & Taking & \\
\hline Taking out health insurance & Taking & \\
\hline Taking out welfare annuity insurance & Taking & \\
\hline Taking out construction industry retirement mutual pension & Not & \\
\hline Taking out retirement allowances or company pension & Taking & \\
\hline Taking out non-legal workers' compensation & Taking & \\
\hline The situation of labor welfare & & 30 \\
\hline Operating years & 57 & \\
\hline Application of the Corporate Rehabilitation Law or Corporate Rehabilitation Law & No & \\
\hline The situation of the continuation of operating of the construction industry & & 60 \\
\hline Conclusion of disaster prevention agreement & & \\
\hline The situation of the contribution to a disaster-prevention activity & Taking & 15 \\
\hline Application of business suspended & No & \\
\hline Application of instructions & No & \\
\hline The situation of compliance & & 0 \\
\hline Execution of inspection & No & \\
\hline Number of certified public accountants etc & 1 & \\
\hline Number of the second class construction industry accountants & 1 & \\
\hline The situation of the accounting of the construction industry & & 4 \\
\hline Research and development expenses & 0 & \\
\hline The situation of research and development & & 0 \\
\hline Number of possession and lease of construction machinery & 0 & \\
\hline The situation of possession of construction machinery & & 0 \\
\hline Registration of ISO9001 & No & \\
\hline Registration of ISO14001 & No & \\
\hline The situation of international organization for standardization & & 0 \\
\hline Score $(W)$ & & 1035 \\
\hline
\end{tabular}


public bodies. The Technical Evaluation Score (TES) of the MLIT is given for each contractor, representing the independent evaluation of construction projects directly controlled by the MLIT.

$$
\mathrm{TES}=\alpha \times(\mathrm{G} 1+\mathrm{G} 2+\mathrm{G} 3)^{\beta},
$$

where

$$
\begin{aligned}
\mathrm{G} 1 & =\sum_{i=1}^{n_{1}}\left\{\left(x_{1 i}-65\right) \times x_{2 i} \times \sqrt{x_{3 i}} \times x_{4 i} \times x_{5 i} \times x_{6 i} \times x_{7 i}\right\} \\
\mathrm{G} 2 & =\sum_{i=1}^{n_{2}}\left\{y_{2 i} \times \sqrt{y_{3 i}} \times y_{4 i} \times y_{5 i} \times y_{7 i}\right\} \\
\mathrm{G} 3 & =\sum_{j=1}^{l} \sum_{i=1}^{m_{i}}\left\{\left(z_{1 i j}-z_{8 j}\right) \times \sqrt{z_{3 i j}} \times z_{6 i j} \times z_{7 i j}\right\} .
\end{aligned}
$$

This section explains the main variables of Equation (2.3). The performance rating indicates the result of construction evaluated by the orderer after the completion of construction on the factors of construction condition, quality and others. The score of the performance rating generally ranges from 65 points to 85 points. The technical difficulty level indicates the difficulty level at which contractors safety complete construction within the predicted construction period while maintaining high quality. It has structure conditions, technical characteristics, natural conditions and other factors. Its value is scored as $1.0,1.25,1.5,1.75$ or 2.0. The scale of the construction indicates the value of construction revenues divided by 1 million yen. If the type of bid on the past construction is GES, the general evaluation is given the point at which the GES point of the construction is transformed within a range of two to three points. The coefficient of the department takes the value 0.5 or 1 according to local requirements and the construction revenue. The coefficient of adjustment is determined on the basis of score of the performance rating. If the performance score is more than or equal to the average score of each orderer, it 
Table 2.7: Variables of Independent Assessment by Orderers

\begin{aligned} & \hline Variables Descriptions \\ & \hline G1 Score of direct control constructions of MLIT \\ & G3 Score of constructions by GES \\ &$n_{1}$ The number of constructions of MLIT \\ &$n_{2}$ The number of constructions by GES \\ &$m_{j}$ The number of constructions of $j$ th local public body \\ &$l$ The number of local public bodies \\ &$x_{1 i}$ Performance rating of $i$ th construction of MLIT \\ &$x_{2 i}$ Technical difficulty levels of $i$ th construction of MLIT \\ &$x_{3 i}$ Scale of the construction of $i$ th construction of MLIT \\ &$x_{4 i}$ General evaluation of $i$ th construction of MLIT \\ &$x_{5 i}$ Coefficient of department of $i$ th construction of MLIT \\ &$x_{6 i}$ Coefficient of adjustment of $i$ th construction of MLIT \\ &$x_{7 i}$ Coefficient of proximateness of $i$ th construction of MLIT \\ &$y_{2 i}$ Technical difficulty levels of $i$ th construction by GES \\ &$y_{3 i}$ Scale of the construction of $i$ th construction by GES \\ &$y_{4 i}$ General evaluation of $i$ th construction by GES \\ &$y_{5 i}$ Coefficient of department of $i$ th construction by GES \\ &$y_{7 i}$ Coefficient of proximateness of $i$ th construction by GES \\ &$z_{1 i j}$ Performance rating of $i$ th construction of $j$ th local public body \\ &$z_{3 i j}$ Scale of the construction of $i$ th construction of $j$ th local public body \\ &$z_{6 i j}$ Coefficient of adjustment of $i$ th construction of $j$ th local public body \\ &$z_{7 i j}$ Coefficient of proximateness of $i$ th construction of $j$ th local public body \\ &$z_{8 j}$ Average of performance rating of $j$ th local public body \\ & \hline\end{aligned}


takes 1 , and if the performance score is less than the average score of each orderer, it takes 0 . The coefficient of proximateness is evaluated by the construction revenues. If the contractor has contracted to perform constructions in the last two years, it takes two. If the contractor has contracted to perform constructions from three to four years ago, it takes one. Parameters $\alpha$ and $\beta$ are determined as the average of Keisin total scores and the average of TES.

To obtain a high score by the independent evaluation basis of the MLIT, the past construction revenue and the performance rating score must be high. This calculation is similar to that of orderers other than the MLIT. The current applying contractors' past construction records are important in orderers' independent assessment.

\subsection{Grading}

Each orderer of public works grades contractors on the basis of the objective examination and their independent assessment.

In the case study, this section explains the grading of general civil engineering construcion in the Kanto Regional Development Bureau, the MLIT. The grading is performed on the basis of the composite score that sums the score of Keisin and the TES, which is the MLIT's independent assessment. In the Kanto Regional Development Bureau, the MLIT, the general civil engineering construction projects and contractors are classified into four levels (A, B, C and D) in Table 2.8. For example, if the composite score of a contractor is more than 3000 points, the contractor is graded A. It can participate in the bid with an estimated price of 720 million yen or more per construction project. However, the contractors graded A cannot participate in bids with an estimated price below 720 million yen. The estimated price of each construction project is secret, but the grade of each construction project is published. For general civil engineering, the upper structure of steel bridges and landscaping and gardening, if the company TES is 0 , the contractor is rated at the lowest grade regardless of the composite score.

The competitive bidding system is separated into the general competitive bidding system and 
Table 2.8: The grading of general civil engineering in Kanto Regional Development Bureau, MLIT

\begin{tabular}{lll}
\hline Grading & Composite score & \multicolumn{1}{c}{ Estimated price } \\
\hline A & 3,000 or more & 720 million yen or more \\
B & $2,580-2,999$ & 300 million yen or more to less than 720 million yen \\
C & $1,600-2,579$ & 60 million yen or more to less than 300 million yen \\
D & 1,599 or less & less than 60 million yen \\
\hline
\end{tabular}

the selective competitive bidding system. All the contractors with the grade corresponding to the estimated price, can participate in the general competitive bidding system. However, only the contractors selected by the orderers can participate in the selective competitive bidding system. The orderers select the contractors with the grade corresponding to the estimated price. This practice prohibits contractors from participating in the higher and lower grade bidding.

\subsection{Discussion}

This section discusses the Keisin and the grading system and compares it with similar systems in other countries.

\subsubsection{Effectiveness of Keisin}

As noted in Section 2.2.1, the surplus of contractors in the market during the postwar period made it difficult for orderers to select suitable contractors. Since the Keisin objective evaluation system has been enacted and institutionalised, orderers have been able to objectively evaluate contractors' comprehensive capability by a national standard. This standardisation is the Keisin's most important role.

As a pre-bid examination system, the bond system has been widely used in the United States as follows. To issue a bond before bids, the contractors' capability must be examined by the guarantee companies and the bond must be submitted to the orderer. The bond guarantees that if the construction firm which obtains the contract cannot complete construction, the guarantee 
company pays the cost to the orderer as subrogation. The examination for the guarantee is regarded as the pre-bid examination. The bond system focuses only on contractor capability.

In Japan, contractors who provide public works are requited not only proper constructions more strictly than contractors who provide private sector constructions, but also social responsibility assurances such as contribution to disaster prevention and labour welfare. Thereby, Keisin evaluates the contractor's comprehensive capability including technical strength and social value. Keisin evaluates contractors on more factors than the bond system.

In fact, Keisin is used not only for the bid entry qualifications of public works, but also when the orderers of private works and financial institutions evaluate construction companies (for details, see Central Council on Construction Contracting (2007)). Because Keisin has the three following advantages, it is considered as an effective index and used for corporate evaluation.

(a) Keisin scores are available on the internet to the public.

(b) Because Keisin imposes penalties for falsified applications, it is reliable.

(c) Because Keisin uses a national standard, construction companies can be easily compared.

Further, the MLIT uses Keisin to promote subscriptions to social insurances. The MLIT checks applicant contractors' subscription to social insurance and gives subscription instructions to contractors who do not take out such insurances. From November 2012 to June 2013, the subscription instruction for social insurance was given to 14,079 contractors, comprising $11.9 \%$ of all contractors who applied for Keisin. In the future, the MLIT has adopted the policy that contractors who do not take out social insurances cannot obtain construction contracts as prime contractors of public works. Its social insurances include pension, medical treatment and employment, and when workers face a risk, it insures their lives in cash or benefits in kind. Thus, Keisin also serves to improve workers' lifelong protection.

Because Keisin evaluates contractors on many factors, it is effective for various purposes. 


\subsubsection{Efficiency of Grading}

The Japanese grading system in public bids ensures competitive bidding among firms with similar scale and capability. Therefore, the grading system fairly segments the contractors and restricts excessive competitions. To protect SMEs, many orderers of public works divide the construction finely, and they order per small task. This split order strategy creates an opportunities for SMEs to bid. If orderers order only large scale construction, only large contractors with higher scores can obtain the construction contracts. However, in split orders, SMEs with lower scores have the opportunity to obtain construction contracts. Moreover, as the bid entry qualifications and bids themselves are conducted for every industry class, even if a company does not do general civil engineering and general building, companies of all industries can also win the construction contract as the prime contractor.

In comparison with other countries, for example, the Florida state highway office in the United States regulates the maximum construction contracts capacity of the contractors who can participate in the bid by contractor's past performance record. In Britain, the maximum of contracts capacity per construction is defined on the basis of the financial strength and the past construction records of the contractors in every industry class.

However, as they do not define the minimum construction revenues, the Japanese grading system is quite novel. It is efficient in that it provides opportunities to obtain construction contract as prime contractors for SMEs and contractors of all industries in addition to the large scale contractors and the contractors of specific industries.

As this section noted, Japanese competitive bid entry qualifications provide many benefits. The orderers of private works and financial institutions use Keisin to evaluate construction companies, and it contributes to improve workers' lifelong protection. Moreover, the Japanese grading system in public bids provides opportunities for SMEs in every industry class to obtain constructions contracts as prime contractors. 


\section{An empirical analysis of the exit of SMEs tendering for public works in the Japanese construction industry}

\subsection{Introduction}

This study empirically analyzes the factors that affect exits of small and medium-sized enterprises (SMEs) from public works, by evaluating construction companies (Keiei Jikou Sinsa or Keisin in Japanese) in Japan. The evaluation of construction companies involves the assessment of contractors bidding for public works projects in Japan. Exit factors are analyzed using the binary logit model. By considering the definition of SMEs given by the Small and Medium-sized Enterprise Basic Act of Japan, this study analyzes only companies with less than 300 million yen of capital. From the data on the evaluation of construction companies, the explanatory variables are the scores of construction company evaluations, financial performance indicators and non-financial performance indicators. As penalties exist for falsified applications, the evaluation data are highly reliable.

From the situation of Keisin applications, this study defines the 'exit' from and 'continuation' of public works for construction companies as follows.

(a) 'Exit' refers to companies that applied for Keisin in one fiscal year but not in the following year; it excludes cases of bankruptcy. 
(b) 'Continuation' refers to companies that applied for Keisin in one fiscal year and again in the following year; it also excludes cases of bankruptcy.

The reason for these definitions is that construction companies that do not apply for Keisin do not become the principal contractors of public works. Therefore, these companies must contract for private works or become subcontractors of public works. Although the subcontractors of public works engage public works, the subcontractors contract exclusively with the principal contractor. From the viewpoint of construction contracts and the payment of construction price, contractors of private works and subcontractors of public works are almost the same. This study therefore regards the construction companies that did not apply for Keisin as having exited from public works because they cannot be principal public works contractors.

Companies that were forced to discontinue their business or went bankrupt differ from continuous companies that exit this market in terms of their corporate activity. Therefore, this study excludes bankrupt companies from its analysis. It defines leaving as follows: a company not engaging in the specified industry regardless of reason, including default (bankruptcy) and business focus.

Moreover, this study explains the reasoning behind analysing construction companies that do not apply for Keisin and exit from public works. Keisin is used not only for bid entry qualifications of public works but also when the orderers of private works and financial institutions evaluate construction companies (for details, see Central Council on Construction Contracting (2007)). Keisin has three advantages.

(a) Keisin scores are available to the public via the Internet.

(b) As Keisin imposes penalties for falsified applications, it is reliable.

(c) As Keisin uses a national standard, construction companies can be easily compared.

Therefore, if construction companies exit from public works and do not apply for Keisin, orderers of private works and financial institutions cannot obtain reliable information or compare 
these companies using a unified national standard. Orderers of private works and financial institutions thus have difficulty in evaluating these construction companies, such as the opacity of accounts.

Furthermore, a company has different credit risks, depending on whether it is a principal contractor of public works, a contractor of private works or a subcontractor of public works. In public works, as orderers are countries, special corporations or local governments, principal contractors rarely have an uncollected debt risk. Moreover, in public works, as part of the construction fee is paid in advance, financial institutions make loans and recover the debt easily. On the other hand, construction companies that contract private works have a greater uncollected debt risk because of the danger of the bankruptcy of orderers or principal contractors. Although the subcontractors of public works are not in danger of the orderers going bankrupt, if the principal contractors paying their construction fee go bankrupt, the subcontractors have an uncollected debt risk. Although few cases of the preservation of debt for subcontractors of public works exist, because of its high cost, it has not become widespread (for details, see Investigative Commission of Support Measures for Preservation of Debt to Subcontractors (2010)). Therefore, the uncollected debt risk for contractors of private works and subcontractors of public works is greater than that for the principal contractor of public works. In addition, loans from financial institutions have a major influence on credit management.

Exits from public works make the evaluation of construction companies difficult for the orderers of private works and financial institutions and affect the credit management of loans from financial institutions. If the present study can determine the factors that affect exits, those parties will be able to predict companies' exit probability and thus evaluate companies by their likelihood of exiting the business. This predictive capability is the present study's primary purpose.

Previous studies on leaving the specified industry focus on the industry organization's viewpoint (see Section 3.2.1 for details), and their definition of leaving includes default (bankruptcy) and exiting for other reasons; thus, they do not distinguish between default (bankruptcy) and exiting. Studies in related areas, such as default and bankruptcy, focus narrowly on specific areas, 
without considering exiting companies that leave to change their business focus. Section 3.2.2 and Section 3.2.3 describe such studies in detail.

The present study distinguishes between default (bankruptcy) and purposeful business transformation exits, focuses on exits and analyzes the factors of exits. This focus constitutes the present study's originality and its research objective.

The results of empirical analysis prove that the Keisin data are useful for the factor analysis regarding company exits. Furthermore, although the Keisin data are considered only for bid entry qualifications of public works, they can be applied to the analysis of the exit of SMEs in the construction industry. Foreign countries introducing such a system of objective evaluation on a unified standard would enable more detailed and reliable examination of actual management conditions. However, little empirical study has been conducted globally on exits from business by SMEs, and thus the present study contributes to the literature on exits of SMEs.

\subsection{Literature Review}

\subsubsection{Studies of Leaving}

This subsection explains the leaving strategy and empirical analysis of leavings. For the most classic study of leaving strategy, Caves and Porter (1976) indicate that leaving strategy is determined by the expected rate of return after leaving and market structures such as barriers to leaving. In addition, Porter (1980) proposes the positioning approach. Companies analyzing the industrial structure and ensuring the optimum position becomes a competitive advantage. Section 3.5 notes that the results of our empirical study are consistent with these leaving strategies.

In the classic empirical analysis of leavings, Mansfield (1962) analyzes four industries in America-steel, petroleum, tires, and cars-using multiple regression analysis. Mansfield (1962) demonstrates that the rate of leavings correlates inversely with the profitability or business size. Moreover, Gibson and Harris (1996) use the binary logit model to investigate manufacturing plants in New Zealand and find that the leaving probabilities of companies increase with shorter 
operating years and higher expense-to-sale ratios.

In Japan, Morikawa (1998) analyzes companies with head offices in Tokyo using micro data from the Basic Survey of Business and Activity. Morikawa (1998) analyzes the determinant factors of leavings by existing enterprises, with the existence of exits as an explained variable and the enterprise characteristics of each company as explanatory variables, using the binary logit model. The results demonstrate that the larger a business is, the less likely it is to leave.

As Section 3.1 notes, these studies focus on leaving the specified industry from the standpoint of the industry organization. The definition of leaving includes default (bankruptcy) and exit, which do not have any distinction.

\subsubsection{Studies of the Construction Industry}

This subsection reviews studies on the construction industry in Japan and the empirical analyses of the company defaults. Regarding the construction industry of Japan, Sakano (2008) analyzes the bidding activity on public works and reveals that the contractors' ability to precisely estimate the bidding price and calculate the construction cost of public works are higher, and the contractors tend to make successful bids. He demonstrates that the estimation ability of bidding price on public works produces stable earnings and results in continuation of public works. However, problems have arisen because of reducing the number of bidders. Tanno, Yokota, Uno and Kato (2008) analyze the bidding activity and demonstrate that increasing the number of bidders negatively affects the bid price. As the number of bidders affects public works, the present study analyzes the factors affecting exit from public works in construction companies.

As mentioned in Section 3.1, although the studies that specialized bidding on public works have examined the Japanese construction industry, no study has addressed exits only from the construction industry.

Among empirical analyses of the company defaults, Russell and Jaselskis (1992) develop a discrete choice model to predict the probability of failure for contractors. They find that probability of failure becomes high when four variables are large: the amount of owner-contractor 
evaluation, whether cost monitoring is performed by the owner, the level of support received by the project manager and the early involvement of the contractor's project manager. They indicate that contract administrators can substantially reduce the probability of failure by increasing the amount of evaluation effort expended to evaluate contractors or the performance of cost monitoring during the construction phase.

Hall (1994) analyzes default factors for 58 contractors in England with 94 explanatory variables, using the binary logit model. Hall (1994) reveals the following two points. First, the variables of human resources inside and outside the company, such as specialist advice, owner characteristics and the existence of workers' technology, greatly affect defaults. Second, the variables of financial management, marketing and strategic management do not affect defaults.

Russell and Zhai (1996) predict contractor failure by examining stochastic dynamics patterns, including percentage changes, trends and volatility for economic and financial variables, and determine that failed contractors have a negative trend and greater volatility in the percentage changes of net worth, gross profit and net working capital. They develop a discriminant function for detecting failed contractors, using six variables: trend of the prime interest rate, future position of new construction value in place, trend of new construction value in place, future position of net worth/total asset, trend of gross profit/total assets and volatility of net working capital/total assets.

Kaplinski (2008) reveals the path of construction companies towards bankruptcy in Poland. Kaplinski (2008) notes that the Z-score index should be adjusted to economic conditions by country or industry and that bankruptcy results from the company's poor financial standing, comprising the company's financial structure, financial liquidity, solvency, adaptation capacity and economic resources, including production potential, capability to generate profit and capability to maximize the company's market value.

Al-Sobiei, Arditi and Polat (2005) examine default strategy and predict the risk of contractor default in Saudi Arabia, applying an artificial neural network and a genetic algorithm to the data of the General Directorate of Military Works, which supervises construction projects. They 
reveal a strategy that could enable large construction company owners to minimize the overall cost of contractor default.

These studies focus on default and bankruptcy in the construction industry. As stated in Section 3.1, they do not examine exiting companies but change their business content.

\subsubsection{Studies of Default Risk of SMEs in Japan}

This subsection reviews studies of credit risk of SMEs in Japan includes the following studies. Omura, Mizukami, Kusumi and Shiogai (2002) analyze the financial characteristics of bankrupt companies and financial institutions' lending action with four financial indicators, using binary logit and hazard models. They perform a high bankruptcy probability prediction and find that the earnings performance of defaulting companies decreases quickly and the amount of debt increases consistently until immediately before bankruptcy.

Fujii and Takemoto (2010) develop a default risk evaluation model based on large-scale data of financial performance indicators. They use the typical financial and macroeconomic variables with a multiperiod logit model and find that the interpretability of the model differs by industry type. They also find that the cash equivalent/total assets ratio, which is the index of liquidity, and the margin/interest expense ratio, which is the index of solvency, are significant explanatory variables. Omura et al. (2002) and Fujii and Takemoto (2010) deal with bankruptcy rather than leavings. As stated in Section 3.1, few studies have examined the leavings of SMEs, and thus our study is particularly meaningful.

\subsection{Keiei Jikou Sinsa (Keisin)}

This section briefly explains Keisin. Companies with capital of less than 300 million yen, i.e., SMEs, comprise approximately $99 \%$ of Japan's construction industry (for details, see Japan Federation of Construction Contractors (2012)).

The acceptance of orders and the execution of projects differ by the type of project. In private 
projects, the orderer chooses the contractor arbitrarily, except for cases of large-scale construction. In contrast, public works projects are commissioned in principle by competitive bidding, and the winning bidder forms a contractual agreement with the orderer. To obtain public works projects, principal contractors must undergo evaluation (hereinafter, Keisin). The Minister of Land or the prefecture governor conducts this evaluation in accordance with Japan's Construction Business Act.

Keisin is the evaluation that contractors which contract directly with orderers for public works construction projects for institutions, must undergo in $\operatorname{Japan}^{1}$. Approximately $30 \%$ of all contractors in Japan have undergone Keisin.

Using national technological, management and social standards, Keisin evaluates the capability of each company that contracts public works projects. As Table 1 reports $^{2}$, Keisin considers (1) the size of business (X1 score and X2 score), (2) business conditions (Y score), (3) technical strength ( $\mathrm{Z}$ score) and (4) other matters (W score). The total score is the weighted sum of the scores:

$$
\text { total score }=0.25 \times \mathrm{X} 1+0.15 \times \mathrm{X} 2+0.2 \times \mathrm{Y}+0.25 \times \mathrm{Z}+0.15 \times \mathrm{W} \text {. }
$$

The X1 and X2 scores reflect the size of the business. The X1 score is based on the average annual construction revenue in every industry for either the last two or last three years. The X2 score comprises two items: shareholder equity and average earnings.

The $\mathrm{Z}$ score indicates construction ability and technical strength. As the $\mathrm{Z}$ score is computed using the prime construction revenue and the number of technical staff for the industry, it is generally proportional to the size of business. The Y score is the index of business conditions and consists of financial performance indicators. The $\mathrm{Y}$ score is also considered to be a measure of financial soundness. The $\mathrm{W}$ score is the evaluation of social value, which includes corporate

\footnotetext{
${ }^{1}$ Ministry of Land. For more information about the claim for Keisin in Japanese and the total score (in Japanese), see http://www.mlit.go.jp/totikensangyo/const/1_6_bt_000161.html/

${ }^{2}$ The author has created this table based on the Central Council on Construction Contracting (2007)
} 
Table 3.1: Keisin items

\begin{tabular}{|c|c|c|}
\hline Item & Evaluation item & Score width \\
\hline $\mathrm{X} 1$ & Construction revenue（industry-classified） & $390 \sim 2268$ \\
\hline $\mathrm{X} 2$ & $\begin{array}{l}\text { Shareholders' equity } \\
\text { Average earnings }\end{array}$ & $454 \sim 2280$ \\
\hline $\mathrm{Y}$ & $\begin{array}{l}\text { Net paying interest/revenue } \\
\text { Debt turnover period } \\
\text { Ordinary income ratio } \\
\text { Gross profit / total capital } \\
\text { Ratio of net worth to fixed assets } \\
\text { Ratio of capital to assets } \\
\text { Cash flow from operations (absolute cost) } \\
\text { Earned surplus (absolute cost) }\end{array}$ & $0 \sim 1595$ \\
\hline $\mathrm{Z}$ & $\begin{array}{l}\text { Number of technical staff（industry-classified） } \\
\text { Prime construction revenue（industry-classified） }\end{array}$ & $450 \sim 2366$ \\
\hline $\mathrm{W}$ & $\begin{array}{l}\text { Labor welfare } \\
\text { The continued operation of the construction industry } \\
\text { Contribution to a disaster-prevention activity } \\
\text { Compliance } \\
\text { The accounting of the construction industry } \\
\text { Research and development }\end{array}$ & $0 \sim 1750$ \\
\hline
\end{tabular}

social responsibility and contributions.

The total Keisin score serves to evaluate competitive bid entry qualifications of public works. For the qualification test, companies are rated using Keisin score and the orderer's original assessment system, including past records of business contracts. This rating affects companies' ability to obtain business contracts, and thus the Keisin score is extremely important. The process of successful bidding for public works projects is as follows. The company that offers a bid below the estimated price, which is a secret maximum price for every project, and offers the lowest price among all offers generally obtains the contract.

Japan's administrative agencies have established penal regulations, such as the suspension of business for 30 days or more, for falsified applications. Furthermore, when a punishment is imposed, Keisin permission is revoked and the offending company is prohibited from obtaining Keisin permission for five years. 


\subsection{Empirical Analysis}

\subsubsection{Overview of the Sample}

The source of the data is Keisin Trend $5^{3}$, which is the Keisin database. In Japan, construction companies must obtain permission from the governor of the prefecture in which their offices are located. Companies with offices in two or more prefectures must obtain permission from the Minister of Land. This study analyzes only companies with their head offices in Setagaya Ward, Tokyo Prefecture, which must obtain permission from the Minister of Land o $r$ the Governor of Tokyo, and which applied for Keisin in 2009. Based on Section 1 of Article 2 of the Small and Medium-sized Enterprise Basic Act, construction SMEs are defined as those with capital of less than 300 million yen or less than 300 employees who have regular employment by Small and Medium Enterprise Agency (2012). This study could not obtain the number of regular employees; therefore, our empirical analysis focuses on companies that have a capital of less than 300 million yen.

This study classifies the companies that applied for Keisin in 2009 into two categories: companies that also applied in 2010 are 'continuation' companies, and companies that did not apply in 2010 (except for cases of bankruptcy) are 'exiting' companies. This study excludes companies with missing values for the variables. As a result, the number of companies included in our analysis is 249 , of which 10 are exiting companies. Industries are classified into 31 types (Table 3.2). Companies that conduct business in two or more industries must undergo Keisin for each type of industry. Variables such as the total score, X1 score, Z score, construction revenue, number of technical staff and prime construction revenue are calculated for each industry type. This study considers the industry with the highest share of construction revenue as the primary industry for each company.

Moreover, in cases where companies that apply for Keisin are general civil engineering or general building, the construction revenue of the relevant industry is also included for each

\footnotetext{
${ }^{3}$ http://www.wise.co.jp/trend-web/
} 
Table 3.2: Industries into 31 types

\begin{tabular}{lll}
\hline General Civil Engineering & Tile, Brick and Block & Machine and Equipment Installation \\
Prestressed concrete & Steel Structure & Heat Insulation \\
General Building & Upper Structure of Steel Bridge & Telecommunication \\
Carpentry & Reinforcement Steel & Landscaping and Gardening \\
Plastering & Paving & Well Drilling \\
Scaffolding, Earthwork and Concrete & Dredging & Fittings \\
Slope Treatment & Sheet Metal & Water and Sewerage Facilities \\
Masonry & Glazing & Fire Protection Facilities \\
Roofing & Painting & Sanitation Facilities \\
Electrical & Waterproofing & \\
Plumbing & Interior Finishing & \\
\hline
\end{tabular}

company. Tokyo Prefecture classifies general civil engineering into eight types of industry and general building into thirteen types of industry. In such cases, as the total score, X1 score and $\mathrm{Z}$ score are based on construction revenue, the scores are high for general civil engineering and general building compared to other types of industry. Because these companies cannot be compared with other types of industry, this study analyzes 29 types of industry, excluding general civil engineering and general building.

\subsubsection{Variables and the Fundamentals of the Statistics}

Let $y_{i}$ be the variable in the following two categories: the value for company $i$ that applied for Keisin in 2009 and 2010 is 0 (continuation), and the value for company $i$ that did not apply in 2010 (excluding bankruptcy) is 1 (exiting). Let $\boldsymbol{x}_{i}$ be the explanatory variable vector of the features of company $i$. The features of the Keisin score, the financial performance indicators, the operating years and other matters are included in $\boldsymbol{x}_{i}$. In this study, the fundamentals of statistics for each variable are given in Table 3.3, Table 3.4 and Table $3.5^{4}$ respectively.

\footnotetext{
${ }^{4}$ Each unit of variable is as follows. Cash flow from operations is 100 million yen; capital is 1000 yen; unemployment insurance takes 0 (Not having) or 1 (Having); and operating years is 1 year
} 
Table 3.3: Fundamentals of the statistics for all samples

\begin{tabular}{lrrrrr}
\hline Variable & Sample size & \multicolumn{1}{l}{ Mean } & \multicolumn{1}{c}{ Std. Dev. } & \multicolumn{1}{l}{ Min } & \multicolumn{2}{l}{ Max } \\
\hline Total score & 249 & 702.1767 & 127.2274 & 442 & 1180 \\
X1 score & 249 & 746.2289 & 156.9534 & 456 & 1283 \\
X2 score & 249 & 617.5863 & 100.168 & 454 & 1044 \\
Y score & 249 & 757.9116 & 200.2187 & 61 & 1107 \\
Z score & 249 & 670.7309 & 150.8376 & 450 & 1375 \\
W score & 249 & 691.004 & 388.5106 & 0 & 1320 \\
Cash flow from operations & 249 & 0.1407912 & 0.5216708 & -1.544 & 4.604 \\
Capital & 249 & 171396.3 & 572522.9 & -95758 & 6218194 \\
Having unemployment insurance & 249 & 0.8514056 & 0.3564046 & 0 & 1 \\
Operating years & 249 & 27.78313 & 13.92698 & 0 & 59 \\
\hline
\end{tabular}

Table 3.4: Fundamentals of the statistics for continuation companies

\begin{tabular}{lrrrrr}
\hline Variable & Sample size & \multicolumn{1}{l}{ Mean } & Std. Dev. & Min & \multicolumn{2}{l}{ Max } \\
\hline Total score & 239 & 707.159 & 126.3226 & 442 & 1180 \\
X1 score & 239 & 749.4393 & 157.9905 & 456 & 1283 \\
X2 score & 239 & 620.6402 & 100.4046 & 454 & 1044 \\
Y score & 239 & 759.9749 & 201.0941 & 61 & 1107 \\
Z score & 239 & 675.364 & 151.6911 & 450 & 1375 \\
W score & 239 & 705.3556 & 380.7641 & 0 & 1320 \\
Cash flow from operations & 239 & 0.147962 & 0.531112 & -1.544 & 4.604 \\
Capital & 239 & 178105.1 & 583450.8 & -95758 & 6218194 \\
Having unemployment insurance & 239 & 0.861925 & 0.345703 & 0 & 1 \\
Operating years & 239 & 28.2636 & 13.85495 & 0 & 59 \\
\hline
\end{tabular}

Table 3.5: Fundamentals of the statistics for exiting companies

\begin{tabular}{lrrrrr}
\hline Variable & Sample size & Mean & Std. Dev. & Min & Max \\
\hline Total score & 10 & 583.1 & 87.39877 & 444 & 731 \\
X1 score & 10 & 669.5 & 109.1709 & 473 & 824 \\
X2 score & 10 & 544.6 & 61.04861 & 454 & 632 \\
Y score & 10 & 708.6 & 180.1001 & 437 & 896 \\
Z score & 10 & 560 & 65.25676 & 459 & 636 \\
W score & 10 & 348 & 434.864 & 0 & 1200 \\
Cash flow from operations & 10 & -0.0306 & 0.074449 & -0.195 & 0.063 \\
Capital & 10 & 11055.8 & 19680.99 & -20310 & 51025 \\
Having unemployment insurance & 10 & 0.6 & 0.516398 & 0 & 1 \\
Operating years & 10 & 16.3 & 10.76052 & 5 & 37 \\
\hline
\end{tabular}




\subsubsection{Analytical Method}

This study analyzes the company features that affect the exits of SMEs. First, it assumes the companies have only two states: exiting or continuation. This study lets the explained variable $y$ be the binary variable that expresses the state of the company: 'continuation' $(y=1)$ or 'exiting' $(y=0)$. If explanatory variables $\boldsymbol{x}$ (financial performance indicators and other indicators) are given, this study assumes that $y$ has Bernoulli distribution. Thus, $P(y=1 \mid \boldsymbol{x})$ expresses the exit probability if $\boldsymbol{x}$ are given.

Second, this study analyzes the explanatory variables that affect the exit probability $P(y=$ $1 \mid \boldsymbol{x} ; \boldsymbol{\beta})$ using the binary logit model, where $\boldsymbol{\beta}$ are parameters. Using the binary logit model, this study describes the relationship between the exit probability and explained variable through the estimated valued of parameters.

When the explained variable is binary, using a linear regression model (called a linear probability model) poses two major problems: that the predicted probability may be outside of $[0,1]$ and that there must be heteroskedasticity (see Winkelmann and Boes (2009) for details). To avoid these problems, this study uses the binary logit model.

The remainder of this section briefly describes the binary logit model (see Winkelmann and Boes (2009) for details).

The explained variable $y$ is a binary variable with values of 0 and 1 . It has the following Bernoulli distribution functions:

$$
f(y \mid \boldsymbol{x})=\pi(\boldsymbol{x})^{y}[1-\pi(\boldsymbol{x})]^{1-y}, \quad y=0,1 .
$$

However, $\pi(\boldsymbol{x})$ is the abbreviation of $P(y=1 \mid \boldsymbol{x})$, which means that $y$ has a value of 1 by conditioning the explaining variable vector $\boldsymbol{x}$.

For the binary logit model, assume that $\pi$ is the conditional probability of Equation (3.2) in 
the following form:

$$
\pi(\boldsymbol{x} ; \boldsymbol{\beta})=\frac{\exp \left(\boldsymbol{x}^{\prime} \boldsymbol{\beta}\right)}{1+\exp \left(\boldsymbol{x}^{\prime} \boldsymbol{\beta}\right)} .
$$

This study uses the maximum likelihood estimation. In this case, the binary probability function can be written as

$$
\ln L(\boldsymbol{\beta} ; y, \boldsymbol{x})=\sum_{i=1}^{n}\left\{y_{i} \ln \pi\left(\boldsymbol{x}_{i} ; \boldsymbol{\beta}\right)+\left(1-y_{i}\right) \ln \left(1-\pi\left(\boldsymbol{x}_{i} ; \boldsymbol{\beta}\right)\right)\right\}
$$

The maximum likelihood estimators are obtained by maximizing $\boldsymbol{\beta}$.

\subsubsection{Model Selection}

This study analyzes the relationship between the explained variable and the explanatory variables using the binary logit model, with $y_{i}$ as the explained variable and $\boldsymbol{x}_{i}$ as the explanatory variables, as discussed in Section 3.4.2. By changing the combination of $\boldsymbol{x}_{i}$, this study establishes models (1)-(5) with the explanatory variables of each model as follows:

(a) Model (1) comprises the total Keisin score as the explanatory variable.

(b) Model (2) comprises the X1 score, Y score and W score, which are the components of the total score. Strictly, the X2 score and Z score also comprise the total score. However, as the correlation between the $\mathrm{X} 1$ score, $\mathrm{X} 2$ score and $\mathrm{Z}$ score is very high, only the $\mathrm{X} 1$ score is adopted in consideration of the multicollinearity problem.

(c) Model (3) comprises the financial performance indicators as the explanatory variable in computing the Keisin.

(d) Model (4) uses the non-financial performance indicators and the operating years used by Gibson and Harris (1996) as the explanatory variables. 
(e) Model (5) comprises the financial and non-financial performance indicators. The nonfinancial performance indicators are incorporated as an extension of model (3).

\subsubsection{Estimated Results and Discussion}

This section considers the estimated results. Table 3.6 reports the sign of the estimated coefficient for each model. In addition, the robust standard errors are used.

Table 3.6: Results of the binary logit analysis

\begin{tabular}{|c|c|c|c|c|c|}
\hline & $\operatorname{model}(1)$ & $\operatorname{model}(2)$ & $\operatorname{model}(3)$ & $\operatorname{model}(4)$ & $\operatorname{model}(5)$ \\
\hline Total score & $\begin{array}{c}-0.0114^{* * *} \\
(0.00382)\end{array}$ & & & & \\
\hline $\mathrm{X} 1$ score & & $\begin{array}{l}-0.00263 \\
(0.00251)\end{array}$ & & & \\
\hline Y score & & $\begin{array}{l}-0.00179 \\
(0.00123)\end{array}$ & & & \\
\hline W score & & $\begin{array}{c}-0.00256^{* *} \\
(0.00130)\end{array}$ & & & \\
\hline Cash flow from operations & & & $\begin{array}{c}-4.732^{* *} \\
(2.161)\end{array}$ & & $\begin{array}{l}-4.749^{*} \\
(2.621)\end{array}$ \\
\hline Capital & & & $\begin{array}{c}-0.0000192^{* * *} \\
(0.00000589)\end{array}$ & & $\begin{array}{r}-0.0000184^{* *} \\
(0.00000768)\end{array}$ \\
\hline Having unemployment insurance & & & & $\begin{array}{l}-1.208^{*} \\
(0.650)\end{array}$ & \\
\hline Operating years & & & & $\begin{array}{c}-0.0642^{* * *} \\
(0.0232)\end{array}$ & $\begin{array}{c}-0.0570^{* *} \\
(0.0290)\end{array}$ \\
\hline Constant & $\begin{array}{l}4.075^{*} \\
(2.268)\end{array}$ & $\begin{array}{c}1.307 \\
(1.885)\end{array}$ & $\begin{array}{c}-2.552^{* * *} \\
(0.345)\end{array}$ & $\begin{array}{l}-0.858 \\
(0.733)\end{array}$ & $\begin{array}{c}-1.405^{* *} \\
(0.579)\end{array}$ \\
\hline Observations & 249 & 249 & 249 & 249 & 249 \\
\hline
\end{tabular}

Model (1) analyzes how the total score affects exiting. The total score gives the exit significant negative influence. To estimate companies' fulfilment capabilities for public works projects, the total score is designed with a subjective standard. Therefore, construction companies with a low capability to perform have a low total score and are rated low overall. The empirical results suggest that such companies tend to exit from the public works industry.

Model (2) analyzes how the X1 score, Y score and W score, which constitute the total score, affect exiting. The analysis reveals that the $\mathrm{W}$ score has a significant negative impact on exiting. The $\mathrm{W}$ score represents the sociality of companies and evaluates the labour welfare situation and compliance of each company. Companies with poor performance are considered to have low W 
scores, which is consistent with the analysis result that companies with low $\mathrm{W}$ scores are more likely to exit. The $\mathrm{X} 1$ score is based on the average annual construction revenue and represents the size of business. The Y score was designed by Central Council on Construction Contracting (2007), which revises Keisin, as the index of the probability with which companies go bankrupt based on financial performance indicators. In this analysis result, the $\mathrm{X} 1$ score and $\mathrm{Y}$ score do not affect exits significantly. Therefore, these scores' influence on exits cannot be determined by construction revenue and the index of bankruptcy.

Next, models (3)-(5) analyze how the financial performance indicators, non-financial performance indicators and their combination affect exits. In model (3), the analysis demonstrates that the cash flow from operations and capital have significant negative impacts on exits. The cash flow from operations is the accumulated cash from operating activities and is given in units of 100 million yen. The cash flow from operations and capital are indices that reflect business size, and the result demonstrates that companies with large cash flows from operations and large amounts of capital are less likely to exit. This result concurs with the studies of Mansfield (1962) and Morikawa (1998), who find that large-scale companies are less likely to exit.

In model (4), the empirical results demonstrate that having unemployment insurance and the number of operating years has a significant negative impact on exit. The result demonstrates that companies with unemployment insurance are less likely to exit, as are those that have been in operation for more years. Having unemployment insurance indicates labour compliance; the purpose of unemployment insurance is stability during workers' unemployment. Thus, the indexes of labour environment and the continuation of company soundness affect exits significantly.

In model (5), the empirical results demonstrate that operating years, cash flow from operations and capital have significant negative impacts on exit. This result is the same as that by Gibson and Harris (1996), who identify the usefulness of adding both financial performance indicators and operating years. Moreover, Keisin uses the X1 score, cash flow from operations and capital as the index of business size. Although the cash flow from operations and capital affect exits, the $\mathrm{X} 1$ score computed from construction revenue does not affect exits. 
Table 3.7: Goodness of fit of the models

\begin{tabular}{lccccc}
\hline & model(1) & model(2) & model(3) & model(4) & model(5) \\
ROC & 0.7948 & 0.7787 & 0.7992 & 0.7494 & 0.8285 \\
Pseudo $R^{2}$ & 0.138 & 0.126 & 0.127 & 0.122 & 0.178 \\
AIC & 76.27 & 81.31 & 79.25 & 79.64 & 77.00 \\
\hline
\end{tabular}

The goodness of fit of the model is obtained by comparing the area under the Receiver Operating Characteristics (ROC) curve, the Pseudo $R^{2}$ and the numerical value of the Akaike Information Criterion (AIC).

The following equations briefly explain these three indicators. Refer to (Winkelmann and Boes, 2009, chapter 3) for details of Pseudo $R^{2}$ and AIC and (Winkelmann and Boes, 2009, chapter 4) for details of ROC.

Let $\ln L_{u}$ be the (maximized) $\log$ likelihood value in the each model and $\ln L_{r}$ be the (maximized) log likelihood value in the constant-only model (in the case all slope parameters are 0). The Pseudo $R^{2}$ is defined as

$$
\text { Pseudo } R^{2}=1-\frac{\ln L_{r}}{\ln L_{u}}
$$

Let $k$ be the number of parameters in each model. AIC is defined as

$$
A I C=-2\left(\ln L_{u}-k\right) .
$$

Let $n_{e}$ be the number of exit companies and $n_{c}$ be the number of continoution companies. The area under ROC is defined as

$$
R O C=\frac{1}{N_{e} N_{n e}} \sum_{i=1}^{N_{e}} \sum_{j=1}^{N_{n} d} I\left(z_{i}-z_{j}\right) .
$$

where $z_{i}$ is predicted exit probability by the estimation of exit companies and $z_{j}$ is that of con- 
tinuation companies and $I(\cdot)$ is the function as follows,

$$
I(x)= \begin{cases}1, & \text { if } x \geq 0 \\ 0, & \text { otherwise }\end{cases}
$$

As Table 3.7 reports, model (5), which uses the financial and non-financial performance indicators, has the largest ROC, indicating that model (5) has the best goodness of fit. Moreover, there is little difference among the ROCs of model (1), which uses the total score as the explanatory variable, model (2), which comprises the X1 score, Y score and W score, and model (3), which comprises the financial performance indicators. Model (4), which uses the non-financial performance indicators, has the worst goodness of fit. However, by combining non-financial indicators with financial indicators (model (5)), ROC becomes larger than in the other models, which indicates that the goodness of fit of model (5) is best. The results for goodness of fit by Pseudo $R^{2}$ are almost the same as those for ROC.

For AIC, the better models are model (1), which uses the total score as the explanatory variable, and model (5), which uses financial and non-financial performance indicators. The total score is the index of a company's public works fulfilment capabilities. The amount of public works construction for which companies can contract is based on the total score. Companies with high scores can bid for large-scale construction. Conversely, companies with low total scores can bid only on small projects. Thus, the results suggest that the probability of exiting from public works is higher for firms with a low total score.

The subject of our analysis is companies with their head office in Setagaya Ward, Tokyo Prefecture, which must obtain the permission of the Minister of Land or the Governor of Tokyo. The sample size is 249 and includes 10 exiting companies. Thus, this study's area is restricted, and the sample size is small. However, in the study of Japanese SMEs beyond the construction industry, the definition of SMEs is ambiguous. Little analysis has used the data and strictly followed the definition of SMEs including the amount of capital and number of employees. No study of exits other than the present study has used the statistical analysis for SMEs, despite the 
fact that all Keisin data is available to the public.

Moreover, as Keisin has established penalties for falsified applications, the data pose few problems, such as the opacity of accounts. Therefore, our study accurately reflects the actual circumstances of Japanese SMEs.

\subsection{Conclusion}

This study empirically analyzes the factors that affect exits using the binary logit model for SMEs in the Japanese construction industry. Based on the Keisin data, the Keisin score, financial performance indicators and non-financial performance indicators are used as the explanatory variables. The results demonstrate that Keisin scores (the total score and W score), financial performance indicators (cash flow from operations and capital), and non-financial performance indicators (having unemployment insurance and operating years) significantly affect SME exits. This result concurs with the studies of Mansfield (1962) and Morikawa (1998), who find that large-scale companies are less likely to leave. Moreover, the results demonstrate that not only financial but also non-financial performance indicators-having unemployment insurance and number of operating years-affect company exits. This result concurs with Gibson and Harris (1996), who identify the usefulness of using operating years as well as financial performance indicators to predict leaving.

This study distinguishes between default (bankruptcy) and exit, focuses on exits and analyzes the factors of exits. However, the results are similar to those of studies of leaving that include default and exit. In general, empirical studies of default (bankruptcy), such as Fujii and Takemoto (2010), reveal that companies with a small equity ratio tend to default. However, this study demonstrates that a small equity ratio does not affect exits significantly. These are findings of this study.

For ROC and Pseudo $R^{2}$, model (5) uses the financial and non-financial performance indicators and has the best goodness of fit. This result demonstrates the usefulness of combining 
financial and non-financial indicators. For AIC, model (1), which uses the total score as the explanatory variable, has the best goodness of fit. Thus, companies with low scores can only bid for small-scale construction.

Conclusions regarding exiting and continuation companies from these results are as follows. Companies with low capital and those that have been operating for fewer years tend to exit. Therefore, this study suggests that younger companies with low capital tend to not participate in bids for public works and prefer to serve as subcontractors for public works or in the private sector. In contrast, construction companies with high total scores that can participate in large-scale construction bids and win such contracts continue in public works contracting. These trends coincide with Porter (1980) positioning approach: companies that rationally enter another industry in which companies are likely to obtain excess profits, having analyzed outside the environment or building a defensible status within the industry, can obtain such profits. Therefore, because the exiting companies seek subcontractors for public works or in the private sector for higher profit, they exit public works. Similarly, the continuation companies continue public works because they can participate in large-scale construction bidding and win those lucrative contracts.

Thus, although the Keisin data are used only for bid entry qualifications of public works, they can reasonably apply to the factor analysis of company exits. Each Keisin score and nonfinancial performance indicators can be used for this analysis, especially having unemployment insurance in the original Keisin value. The Keisin system is useful in determining factors' influence on exit. Foreign countries introducing such a system of objective evaluation on a unified standard would enable more detailed and reliable examination of actual management conditions.

Following the definition of SMEs, this study analyses only companies with capital of less than 300 million yen. As Keisin penalties have been established for falsified applications, the data have high reliability. Therefore, the data present few problems, such as the opacity of accounts. Thus, our study accurately reflects the actual conditions of Japanese SMEs and contributes to the literature on SME exits from an industry.

However, this study was restricted to the construction industry, to a single fiscal year and to 
Setagaya Ward, Tokyo Prefecture. A further direction of study would extend the analysis to other industries and areas, which would allow us to determine the factors affecting the defaults and exits of SMEs more comprehensively. Further, analyzing data for two or more fiscal years as panel data would indicate how changes in company financial performance indicators defaults and exits. 


\section{Default or Exit?: Empirical Study on SMEs in the Japanese Construction Industry}

\subsection{Introduction}

\subsubsection{Background and Identification of this Study}

This study empirically analyses the factors that affect the defaults and exits of prime contractors in the public works of small and medium-sized enterprises (SMEs) in the Japanese construction industry. Using construction company evaluation (Keiei Jikou Sinsa or Keisin) data in Japan as a basis, the factors are analysed using the multinomial logit model. In this case, Keisin is a part of the necessary pre-examination of contractors bidding on public works projects in Japan. A notable feature of this study is the distinction that it highlights between defaults and exits. Default companies differ greatly from exit companies in terms of corporate activity. However, existing studies do not distinguish these two characteristics.

The present condition of Japan's construction industry and SMEs is summarised as follows. In line with the definition of SMEs by the Small and Medium-sized Enterprise Basic Act of Japan, this study analyses only companies with a capital of 300 million yen (approx. US\$ 3 million) or less. These companies comprise roughly $99 \%$ of Japan's construction industry (for details, see the Japan Federation of Construction Contractors (2012)). The market size of Japan's construction industry is decreasing. However, since the construction industry forms $8 \%$ of the 
total number of persons engaged, the construction industry is an important industry that still contributes to the stability of employment.

As for the actual structure in the construction industry (for details, see the Ministry of Land and Tourism (2012)), the number of contractors that contract subcontracted construction projects account for $79.2 \%$ of the whole, and the number of contractors where subcontract revenue occupies $50 \%$ or more account for $49.6 \%$. Furthermore, the contractors where dealings with one specific prime contractor occurs $50 \%$ or more account for $31.7 \%$ among contractors that contract subcontracted construction projects, and the exclusive ratio tends to increase as the capital decreases.

Overall, these statistics reflect the increasing dependence on subcontractors and the stratification of the subcontract structure by prime contractors. Moreover, the public works ordering ratio, which accounts for the construction revenue of public works among the entire construction industry in Japan, is $30.4 \%$. When classifying companies with regard to capital, the ratio of the companies with capital of more than 30 million yen but less than 50 million yen is $40.8 \%$ (highest in the class) and of those with capital of more than 50 million yen but less than 100 million yen is $31.5 \%$ (second highest in the class). In contrast, the ratio of the companies with capital of less than five million yen is $20.3 \%$ (lowest in the class).

This study aims to focus on contractors that contract public works construction projects. Preventing several major contractors from controlling the bidding of public works projects can ensure that a certain number of other participants are involved. Therefore, analysing the factors that affect the defaults or exits of SMEs can effectively contribute to the stable supply of public services and the fair competition of bids.

\subsubsection{Definition of Exit and Default and Data Availability of SMEs}

In general, in an empirical study on the activities of SMEs, identifying exits and acquiring data are extremely difficult. However, by using the Keisin data in this study, these two problems are resolved. In Japan, the companies that hope to be prime contractors in public works are required 
to apply for Keisin (for details, see Section 4.3).

Based on the Keisin applications, this study defines the default, exit and continuation of public works for construction companies, as follows (see Figure 4.1).

(a) Default refers to companies that applied for Keisin in a certain fiscal year, but not in the following year, and companies that were either forced to discontinue their business or went bankrupt.

(b) Exit refers to companies that applied for Keisin in a certain fiscal year, but not in the following year, and companies that are not cases of default.

(c) Continuation refers to companies that applied for Keisin in a certain fiscal year as well as in the following year and companies that are not cases of default.

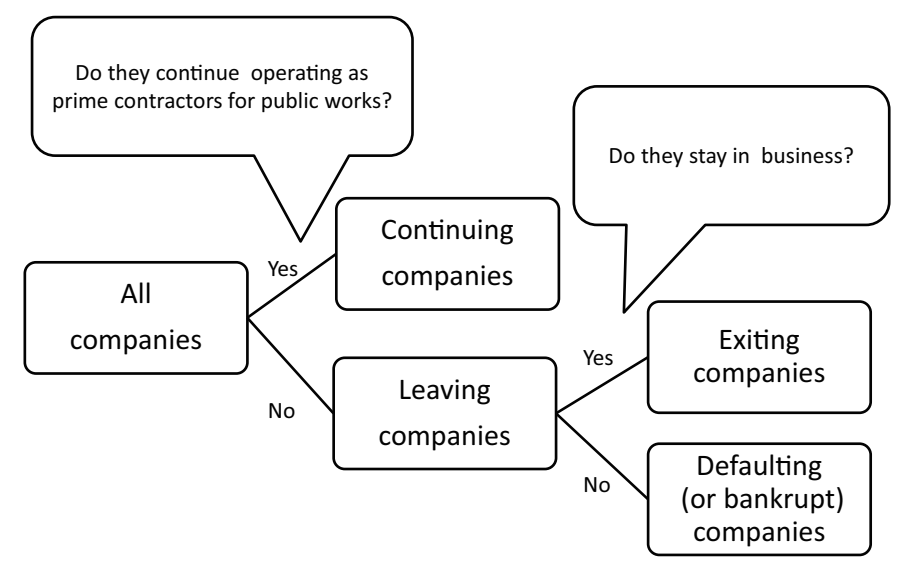

Figure 4.1: Definitions of default and exit

The reason for these definitions of default and exit is as follows. Default and exit companies are the same in terms of not applying for Keisin in the following year. However, the default companies that were either forced to discontinue their business or went bankrupt are quite different from exit companies in terms of corporate activity. Therefore, this study examines the characteristics of default and exit companies. 
In addition, the reason for defining exit as above is as follows. Construction companies that do not apply for Keisin cannot become prime contractors of public works. Therefore, such companies have to take up private works or become subcontractors for public works. Although these subcontractors are still engaged in public works, they have to contract with prime contractors for the construction and payment of construction costs. That is, from the viewpoint of construction contracts and payment of construction costs, the contractors of private works and subcontractors of public works are relatively the same. Therefore, this study considers the construction companies that did not apply for Keisin as having exited prime contractors of public works.

Consideration of exits from the viewpoint of risk is shown as follows. A company has different credit risks depending on whether it is the prime contractor of public works, the contractor of private works or the subcontractor of public works. In public works, since orderers consist of countries, special corporations or local governments, prime contractors rarely have an uncollected debt risk. Moreover, in public works, since part of the construction fees is paid in advance, financial institutions provide loans and recover the debt easily. Conversely, the construction companies that contract private works have a greater uncollected debt risk due to the danger of bankruptcy of orderers or prime contractors. Although the subcontractors of public works are not in danger of the orderers going bankrupt, if the prime contractors paying the construction fees go bankrupt, then the subcontractors have an uncollected debt risk. Although there have been isolated cases of debt preservation for subcontractors of public works (due to its high cost), it has not become widespread (for details, see the Investigative Commission of Support Measures for Preservation of Debt to Subcontractors (2010)). Therefore, compared with the prime contractor of public works, the uncollected debt risk is large for contractors of private works and subcontractors of public works. In addition, loans from financial institutions have a major influence on credit management, and exits from public works make the evaluation of construction companies difficult for the orderers of private works and financial institutions. This can have an effect on the credit management of loans from financial institutions. If this study can determine which factors affect exits, then it will be possible to predict the exit potential of 
certain companies and evaluate them by considering this potential.

Note that the majority of SMEs are privately held companies whose stocks are not traded on public exchanges and have no obligation to open their data.

From the viewpoint of data availability, this study explains the reasoning behind analysing the construction companies that do not apply for Keisin and exit public works. Keisin is not only used for the bid entry qualifications of public works, but also when the orderers of private works and financial institutions evaluate construction companies (for details, see the Central Council on Construction Contracting (2007)). Keisin includes three particular merits.

(a) Keisin scores are available to the public on the Internet.

(b) Since Keisin imposes penalties for falsified applications, it is reliable.

(c) Since Keisin uses a national standard, construction companies can be easily compared.

Therefore, if construction companies exit public works and do not apply for Keisin, then orderers of private works and financial institutions cannot obtain reliable information or compare these companies by a unified national standard. Furthermore, orderers of private works and financial institutions face problems when evaluating these construction companies, such as opacity of accounts. Therefore, since the Keisin data include few problems, using these data in this study can accurately reflect the actual situation of construction SMEs in Japan.

\subsubsection{Originality and Outline of this Study}

Although various studies are explained in detail in the Section 4.2, the apparent differences of this study are as follows. For example, the studies regarding leaving the specified industry from the standpoint of industry organisation are called Section 4.2.2. The definition of leaving includes defaults (bankruptcies) and exits (see Figure 4.1). Thus, they do not distinguish between these two aspects. Next, the studies concerning defaults and bankruptcies are referred to as Section 4.2.1 and Section 4.2.3, respectively. These two sections do not consider exit companies 
that are leaving, but change their business contents. The present study distinguishes between defaults (bankruptcies) and exits, focuses on exits and analyses their factors.

The remainder of this paper is organized as follows. The Section 4.2 presents the Studies of Default, Leaving and SMEs in Japan, while Section 4.3 briefly explains the overall process. The Section 4.4 examines the statistical methods used in this study, and the Section 4.5 shows the empirical study results. Finally, the Section 4.6 discusses the results and presents the limitations as well as future studies.

\subsection{Literature Review}

This section reviews several typical studies regarding defaults and leavings. Furthermore, it discusses the existing studies on credit risk in the construction industry and SMEs in Japan.

\subsubsection{Studies of Default}

The most well-known default risk measurement method that uses financial performance indicators is the Z-score model introduced by Altman (1968), which is a default prediction model that utilises a linear discriminant analysis. Altman (1968) derived the discriminant for five financial performance indicators as explanatory variables for manufacturers. This model can distinguish between the default and non-default companies with high precision through an empirical analysis. The study of the prediction of default probability using the binary logit model by Ohlson (1980) is the most classic example of applying logit models in this field. Psillaki, Tsolas and Margaritis (2010) showed that non-financial performance indicators can provide useful prior information regarding the defaults of companies. In this case, they analysed companies in the manufacturing and growth industries in France from 2000 to 2004 and utilised the binary logit and ordered logit models for default predictions. Their empirical analysis revealed that the nonefficiency of management, a non-financial performance indicator, is an important variable for companies with regard to financial crises. 
For the empirical analysis of defaults and default strategy in the construction industry, Russell and Jaselskis (1992) developed a discrete choice model to predict the probability of failure for contractors. They indicated that contract administrators can substantially reduce the probability of failure by increasing the amount of evaluation effort expended to evaluate contractors or the performance of cost monitoring during the construction phase. Hall (1994), using the binary logit model, analysed the default factors for 58 contractors in England with 94 explanatory variables and revealed the following two points. First, the variables of human resources inside and outside the company, such as specialist advice, owner characteristics and the existence of workers' technology, can greatly affect defaults. Second, the variables of financial management, marketing and strategic management did not affect defaults. Abidali and Harris (1995) analysed the methodology for predicting company failure in the construction industry and used Z-score (i.e. the system combines financial ratio analysis) and the A-score (i.e. the non-financial analysis based on management ability). Abidali and Harris (1995) concluded that there is a link between the $\mathrm{Z}$ and $\mathrm{A}$-scores.

Moreover, Russell and Zhai (1996) predicted contractor failure by examining stochastic dynamics patterns, such as percentage changes, trends and volatility for economic and financial variables, and found that failed contractors have a negative trend and larger volatility in the percentage changes of net worth, gross profit and networking capital. Kale and Arditi (1999) analysed the defaults of contractors in the United States and found an age-dependent default pattern where the risk of default increases initially with the company's age, reaches a peak and decreases as the company grows older. Moreover, Kaplinski (2008) focused on the route of construction companies towards bankruptcy in Poland. Kaplinski (2008) mentioned that the Z-score index should be adjusted to economic conditions of the country or industry and that bankruptcy results from the poor financial standing of a company. In their study of default strategy, AlSobiei et al. (2005) predicted the risk of contractor default in Saudi Arabia by using the files of the General Directorate of Military Works (GDMW) of the Kingdom of Saudi Arabia, which supervise the construction projects by an artificial neural network and a genetic algorithm. They 
showed that there is a strategy that allows large construction owners to minimise the overall cost of contractor defaults. These aforementioned studies focused on defaults and bankruptcies in the construction industry.

Huang (2009) analysed the application of structural models of credit risk by using market and accounting data of public construction firms in Taiwan. Huang (2009) indicated that structural models of credit risk are applied for quantitatively predicting contractor default probabilities, and that Leland and Toft (1996) explained default probability adequately.

As mentioned in the Introduction, the studies of Altman (1968), Ohlson (1980), Psillaki et al. (2010), Russell and Jaselskis (1992), Hall (1994), Russell and Zhai (1996), Kale and Arditi (1999), Kaplinski (2008) and Huang (2009) concern bankruptcies rather than leavings. In addition, they do not consider the exit companies that leave and change their business contents.

\subsubsection{Studies of Leaving}

For the classic empirical analysis of leaving, Mansfield (1962) analysed leavings in four American industries (steel, petroleum, tires and cars) by using multiple regression analysis. Mansfield (1962) showed that as the rate of leaving decreases, the profitability or business size increases. Moreover, Gibson and Harris (1996) used the binary logit model for manufacturing plants in New Zealand and showed that the leaving probability of companies increases as the operating years decrease and the expense-to-sale ratio increases. Morikawa (1998) analysed the companies with head offices in Tokyo by using microdata from the Basic Survey of Japanese Business Structure and Activities. Using the binary logit model, Morikawa (1998) analysed the determinant factors of leavings with the existence of exits as the explained variables and the enterprise characteristics of each company as the explanatory variables. The results show that the larger the size of a business, the less likely the company will leave existing enterprises.

With regard to studies of leaving in the construction industry, Chiang, Tang and Leung (2001) examined the market structure of four different sectors in Hong Kong: private building, public building, property development and civil engineering. Chiang et al. (2001) indicated that 
the lack of technological demand and supply has led to easy market entries and leavings in the private building sector. Moreover, Oral and Mistikoglu (2007) examined the factors affecting competition in the Turkish brick industry and described the present condition in which the industry is dominated by SMEs carrying out labour intensive production. They also indicated that barriers to entries and leavings for national brick makers are low since there are no government regulations.

As mentioned in the Introduction, Mansfield (1962), Gibson and Harris (1996), Morikawa (1998), Chiang et al. (2001) and Oral and Mistikoglu (2007) focused on leavings in specific industries from the standpoint of industry organisation. As stated earlier, the definition of leaving includes defaults (bankruptcies) and exits. In this regard, these aforementioned studies do not distinguish these two behaviors.

\subsubsection{Studies of SMEs in Japan}

Concerning the study of SMEs in Japan, Omura et al. (2002) analysed the financial characteristics of bankruptcy companies and the lending actions of financial institutions with four financial indicators by using the binary logit and hazard models. They performed high bankruptcy probability predictions and showed that the earnings performance of defaulting companies decreases quickly and the amount of debt increases consistently until just before bankruptcy occurs. Moreover, Fujii and Takemoto (2010) developed a default risk evaluation model based on the largescale data of financial performance indicators. They also used the typical financial and macroeconomic variables with the multi-period logit model, and found that the interpretability of the model differs by industry type. In addition, they showed that the cash equivalent/total assets ratio, the index of liquidity, the margin/interest expense ratio and the index of responsibility are significant explanatory variables. Hibiki, Ogi and Toshiro (2009) pointed out the usefulness of adding both financial performance indicators and operating years to improve the scoring model for small businesses. According to their study, the default rate of companies is the highest for those with an operating period of less than five years, gradually falls to an average value from 5 
to 15 years and becomes stable up to 35 years. Furthermore, it increases gradually after 35 years and falls again after 50 years.

Omura et al. (2002), Fujii and Takemoto (2010) and Hibiki et al. (2009) focused on bankruptcies rather than leavings. There have been limited studies on the exits of SMEs, and thus, the present study is particularly meaningful.

\subsection{Keisin}

This section provides an overview of Keisin. Construction work is separated into public works projects and private projects. The acceptance of orders and the execution of work differ by project types. In private projects, the orderer chooses the contractor arbitrarily, except for largescale construction. On the other hand, public works projects are carried out by competitive bidding, in principle, and the successful bidder enters into a contract. In order to bid for public works projects, the prime contractors must be evaluated by Keisin. This evaluation is conducted by the Ministry of Land, Infrastructure, Transport and Tourism (MLIT) or the prefecture governor according to Japan's Construction Business Act. Approximately $30 \%$ of the contractors in Japan have gone through the Keisin process.

By the standard of national unification from the technological, management and social viewpoints, it is a system where Keisin evaluates the capability of the company that contracts public works projects. As Table 4.1 shows, the company is evaluated and scored on the basis of the following items: (1) size of the business (X1 and X2 scores), (2) business conditions (Y score), (3) technical strength (Z score), and (4) other matters (W score).

Then, the total score, as seen in Equation (4.1), is the weighted sum of the scores:

$$
\text { Total score }=0.25 \times \mathrm{X} 1+0.15 \times \mathrm{X} 2+0.2 \times \mathrm{Y}+0.25 \times \mathrm{Z}+0.15 \times \mathrm{W} .
$$

The size of business is reflected in the $\mathrm{X} 1$ and $\mathrm{X} 2$ scores. The $\mathrm{X} 1$ score is based on the average annual construction revenue in every industry for the last two or three years. The average revenue 
Table 4.1: Keisin Items

\begin{tabular}{|c|c|c|}
\hline Item & Evaluation Item & Score Width \\
\hline $\mathrm{X} 1$ & Construction revenue (industry-classified) & $390 \sim 2268$ \\
\hline $\mathrm{X} 2$ & $\begin{array}{l}\text { Shareholders' equity } \\
\text { Average earnings }\end{array}$ & $454 \sim 2280$ \\
\hline $\mathrm{Y}$ & $\begin{array}{l}\text { Net paying interest / revenue } \\
\text { Debt turnover period } \\
\text { Ordinary income ratio } \\
\text { Gross profit / total capital } \\
\text { Net worth to fixed assets ratio } \\
\text { Capital-to-asset ratio } \\
\text { Cash flow from operations (absolute cost) } \\
\text { Earned surplus (absolute cost) }\end{array}$ & $0 \sim 1595$ \\
\hline $\mathrm{Z}$ & $\begin{array}{l}\text { Number of technical staff (industry-classified) } \\
\text { Prime construction revenue (industry-classified) }\end{array}$ & $450 \sim 2366$ \\
\hline $\mathrm{W}$ & $\begin{array}{l}\text { Situation of labour welfare } \\
\text { Situation of continuing the operation of the construction industry } \\
\text { Situation of contribution to a disaster-prevention activity } \\
\text { Situation of compliance } \\
\text { Situation of accounting for the construction industry } \\
\text { Situation of research and development }\end{array}$ & $0 \sim 1750$ \\
\hline
\end{tabular}

can be computed for either the latest two years or three years arbitrarily. The X2 score consists of two items: shareholders' equity and average earnings.

The $\mathrm{Z}$ score indicates the construction ability and technical strength. Since the $\mathrm{Z}$ score is computed from the prime construction revenue and the number of technical staff members in the industry, it is generally proportional to the size of the business. The Y score is the index of business conditions and includes financial performance indicators. The Y score is also regarded as a measure of financial soundness. Finally, the W score is the measure of sociality, which includes corporate social responsibility and contribution.

The total score is used to examine the competitive bid entry qualifications for public works projects. Regarding the qualification test, companies are rated on the basis of the Keisin score and their independent assessment system of orderers, such as the past records of business contracts. This rating affects the companies' ability to obtain business contracts, and thus, the Keisin score plays an important role. The structure of a successful bid for public works projects is as 
follows. The company that offers a bid below the estimated price (the secret maximum price of the project) and the lowest price among all offers generally obtains the contract. Finally, Japan's administrative permission agencies have established penal regulations such as suspension of business for 30 days or more for falsified applications. Furthermore, when a punishment is imposed, any Keisin permission is revoked and the company is prohibited from obtaining further Keisin permission for five years.

\subsection{Methodology}

\subsubsection{Analytical Method}

This study analyses the company features affecting the defaults and exits of SMEs by using the multinomial logit model. This section briefly describes the multinomial logit model (for details, see Winkelmann and Boes (2009, Chapter 5) and Cameron and Trivedi (2005, Chapter 15)).

Multinomial variables are characterised by a set of mutually exclusive and exhaustive nonordered categories. Each category usually represents the outcome of the choice or state of individuals or companies in the context of economics. Multinomial models are used to analyse the factors that affect the probability of the outcome of the choice or state. The multinomial logit model is the simplest multinomial model since computations are relatively uncomplicated and parameter estimates are easier to interpret.

Let

$$
\pi_{j}(\boldsymbol{x})=P(y=j \mid \boldsymbol{x})
$$

denote the probability that an individual or a company chooses alternative $j$ given characteristics $\boldsymbol{x}$ (explanatory variables), where $\boldsymbol{x}$ has dimension $(k+1) \times 1$.

Assume that there are $J$ unordered outcomes of the explained variable $y$. Then, let it specify the relationship between the probabilities and the individual or company characteristics $\boldsymbol{x}$ more accurately as between the probabilities and linear index $\boldsymbol{x}^{\prime} \boldsymbol{\beta}_{j}$ with parameter vector $\boldsymbol{\beta}_{j}$ for $j=$ 
$1,2, \ldots, J$. The parameters allow the effect of a change in one regressor to be different for each outcome probability.

For $j=2,3, \ldots, J$, this study assumes

$$
\begin{aligned}
& \pi_{1}(\boldsymbol{x} ; \boldsymbol{\beta})=\frac{1}{1+\sum_{r=2}^{J} \exp \left(\boldsymbol{x}^{\prime} \boldsymbol{\beta}_{r}\right)} \\
& \pi_{j}(\boldsymbol{x} ; \boldsymbol{\beta})=\frac{\exp \left(\boldsymbol{x}^{\prime} \boldsymbol{\beta}_{j}\right)}{1+\sum_{r=2}^{J} \exp \left(\boldsymbol{x}^{\prime} \boldsymbol{\beta}_{r}\right)}
\end{aligned}
$$

where $\boldsymbol{x}$ is a $k+1$-dimensional variable vector and $\boldsymbol{\beta}=\left(\boldsymbol{\beta}_{2}, \ldots, \boldsymbol{\beta}_{J}\right)$. This study allows $\boldsymbol{\beta}_{1}=0$ in order to reduce the dimension and identify the parameter. This category is called 'the base category'.

This study also uses maximum-likelihood estimation. In this case, the multinomial probability function can be written as

$$
f(y \mid \boldsymbol{x} ; \boldsymbol{\beta})=\pi_{1}(\boldsymbol{x} ; \boldsymbol{\beta})^{d_{1}} \ldots \pi_{J}(\boldsymbol{x} ; \boldsymbol{\beta})^{d_{J}}=\prod_{j=1}^{J} \pi_{j}(\boldsymbol{x} ; \boldsymbol{\beta})^{d_{j}}
$$

where the probabilities $\pi_{j}(\boldsymbol{x} ; \boldsymbol{\beta})$ are given by Equation (4.4). $d_{j}$ is defined as a binary indicator with

$$
d_{j}= \begin{cases}1 & \text { if the individual or company chooses alternative } j(y=j) \\ 0 & \text { otherwise }\end{cases}
$$

Assuming a sample of $n$ independent pairs of observations $\left(y_{i}, \boldsymbol{x}_{i}\right)$, this study writes the loglikelihood function of the sample as

$$
\ln L(\boldsymbol{\beta} ; \boldsymbol{y}, \boldsymbol{x})=\sum_{i=1}^{n} \sum_{j=1}^{J} d_{i j} \ln \pi_{j}\left(\boldsymbol{x}_{i} ; \boldsymbol{\beta}\right) .
$$

The maximum-likelihood estimators are obtained by maximising Equation (4.7).

Next, the interpretation of the parameters is explained. The odds of alternative $j$ versus the 
base category are written as follows

$$
\frac{\pi_{j}(\boldsymbol{x} ; \boldsymbol{\beta})}{\pi_{1}(\boldsymbol{x} ; \boldsymbol{\beta})}=\exp \left(\boldsymbol{x}^{\prime} \boldsymbol{\beta}_{j}\right), \quad J=2, \ldots, J
$$

The effect of an increase in the $l$-th explanatory variable by $\Delta x_{j}$ on the odds can be expressed by the factor change in the odds, as follows

$$
\frac{\exp \left(\boldsymbol{x}^{\prime} \boldsymbol{\beta}_{j}+\Delta x_{l} \beta_{j l}\right)}{\exp \left(\boldsymbol{x}^{\prime} \boldsymbol{\beta}_{j}\right)}=\exp \left(\Delta x_{l}^{\prime} \beta_{j l}\right)
$$

where $\beta_{j l}$ is the $l$-th element of the parameter vector $\boldsymbol{\beta}_{j}$. For one unit change in $x_{l}, \Delta x_{l}=1$, the odds of alternative $j$ relative to the base category change by the factor $\exp \left(\beta_{j l}\right)$, which is called the 'odds ratio'. For example, a positive coefficient $\beta_{j l}$ implies that the odds ratio is larger than one, and that increasing $x_{l}$ raises the probability of category $j$ relative to the probability of the base category.

The multinomial logit model is a simple and useful model. However, it is valid only in the case of $y$ occurring in parallel. This condition is called the 'IIA condition', and the Hausman test can examine the realisation of this condition.

In the multinomial logit model, the goodness of fit of the model can compare the numerical value of the Akaike Information Criterion (AIC) and Pseudo $R^{2}$. Let $\ln L_{u}$ be the (maximised) log-likelihood value in each model and $\ln L_{r}$ be the (maximised) log-likelihood value in the constant-only model (in the case where all slope parameters are 0 ). Pseudo $R^{2}$ is defined as

$$
\text { Pseudo } R^{2}=1-\frac{\ln L_{r}}{\ln L_{u}}
$$

Pseudo $R^{2}$ increases as explanatory variables are added for models fitted by maximum-likelihood estimation. 
Let $k$ be the number of parameters in each model. Then, AIC is defined as

$$
A I C=-2\left(\ln L_{u}-k\right)
$$

Since a higher log-likelihood is preferred, a smaller AIC is preferred. $k$ in Equation (4.11) is regarded as the penalty for the number of model parameters.

\subsubsection{Data and Variables}

The source of these data is Keisin Trend 5 from the Keisin database.

In Japan, for undertaking construction, companies must obtain permission from the governor of the prefecture in which the companies' offices are located. Companies that have offices in two or more prefectures must obtain permission from the Minister of Land, Infrastructure, Transport and Tourism. This study analyses the companies that have their head offices in Setagaya Ward, Tokyo Prefecture, and must obtain permission from the Minister of Land, Infrastructure, Transport and Tourism or the governor of the prefecture.

According to Article 2, Section 1, of the Small and Medium-sized Enterprise Basic Act, construction SMEs are defined as those with a capital of 300 million yen or less or 300 or fewer employees with regular employment, as defined by the Small and Medium Enterprise Agency (2012). In this study, obtaining the number of regular employees is impossible. Therefore, this study focuses on the companies that have a capital of 300 million yen or less.

Furthermore, this study classifies the companies that applied for Keisin in 2009 into three categories: continuation, default and exit companies. The companies that applied for Keisin in 2010 are continuation companies, while those that did not apply and were forced to discontinue their business or went bankrupt are default companies. The remainder are exit companies. This study also uses the explanatory variables in 2009 and excludes the companies with missing variables from this analysis. As a result, the number of companies considered in this analysis is 366, with 4 default and 13 exit companies. 
The industries are classified into 31 types. The companies that conduct business in two or more industries must apply for Keisin in each type of industry. The variables such as total score, $\mathrm{X} 1$ score, $\mathrm{Z}$ score, construction revenue, number of technical staff and prime construction revenue are calculated for each type of industry. This study considers the type of industry with the highest share of construction revenue as the primary type for each company. In order to calculate the numerical value for each industry type, this study applies the numerical value of the primary type of industry for the total score, $\mathrm{X} 1$ score and $\mathrm{Z}$ score and the sum of the numerical value of all industry types for construction revenue, number of technical staff and prime construction revenue.

\subsubsection{Models with Anticipations}

Let $y_{i}$ be the explained variables in the following three categories. The value for company $i$ that applied for Keisin in 2009 and 2010 is 0 (continuation). The value for company $i$ that $\operatorname{did}$ not apply for Keisin in 2010 and was forced to discontinue business or went bankrupt is 1 (default). The value of the remainder company is 2 (exit). Let $\boldsymbol{x}_{i}$ be the explanatory variable showing the characteristic of company $i$ in 2009. The features of the Keisin score, financial and non-financial performance indicators are included in $\boldsymbol{x}_{i}$. In this study, the fundamentals of statistics for each variable are given in Table 4.2.

Table 4.2: Fundamentals of Statistics

\begin{tabular}{lrrrrr}
\hline Variable & Sample Size & Mean & Std. Dev. & Min & Max \\
\hline Total score & 366 & 715.4508 & 134.353 & 404 & 1222 \\
X1 score & 366 & 763.7732 & 167.255 & 390 & 1409 \\
Y score & 366 & 739.918 & 199.6095 & 61 & 1107 \\
W score & 366 & 722.7869 & 380.394 & 0 & 1320 \\
Capital & 366 & 25004.56 & 26580.07 & 2000 & 250000 \\
Earned surplus (absolute cost) & 366 & 1.411683 & 4.881805 & -3 & 60.147 \\
Debt turnover period & 366 & 6.136402 & 4.478724 & 0.9 & 18 \\
Taking out unemployment insurance & 366 & 0.863388 & 0.343907 & 0 & 1 \\
Operating years & 366 & 29.95082 & 14.65635 & 0 & 59 \\
\hline
\end{tabular}

This analysis aim to determine the company features that affect the defaults and exits of SMEs. In other words, this study analyses the relationship between the explained variable $y$ and the 
explanatory variables $\boldsymbol{x}$. Since $y_{i}$ is a multinomial variable, this study employs the multinomial logit model with robust standard errors for analysis. In this study, the 'continuation' $(y=0)$ is set as the base category. As mentioned in the Section 4.4, in order to use the multinomial logit model, the IIA condition must be satisfied. In these data, the IIA assumption is not rejected in the Hausman test. Thus, the IIA condition is satisfied.

By changing the combination of the explanatory variables $\boldsymbol{x}_{i}$, this study sets Models (1)-(5) and anticipates the results as follows.

The explanatory variable of Models (1) and (2) are the Keisin scores, and those of Models (3)-(5) are the financial and non-financial performance indicators selected from the Keisin data. The selection criteria are the goodness of fit of the model and the significance of each variable, while the financial performance indicators are accounting titles and financial ratios. Finally, the non-financial performance indicators are other Keisin items without the Keisin scores. The reason for including non-financial performance indicators is based on the results of Psillaki et al. (2010), where non-financial performance indicators are useful for the prediction of defaults. The sign of the anticipated coefficient is given in Table 4.3.

Table 4.3: Sign of Anticipated Coefficient

\begin{tabular}{l|l|cc}
\hline & & Default & Exit \\
\hline Model (1) & Total score & & - \\
\hline \multirow{2}{*}{ Model (2) } & X1 score & + & - \\
& Y score & - & \\
& W score & - & \\
\hline \multirow{2}{*}{ Model (3) } & Capital & + & - \\
& Earned surplus (absolute cost) & + & - \\
& Debt turnover period & + & \\
\hline \multirow{2}{*}{ Model (4) } & Taking out unemployment insurance & - & \\
& Operating years & - & - \\
\hline \multirow{2}{*}{ Model (5) } & Capital & + & - \\
& Earned surplus (absolute cost) & + & - \\
& Debt turnover period & + & \\
& Operating years & - & - \\
\hline
\end{tabular}


(a) Model (1) includes only the total score as the explanatory variable.

The total score shows the capability of construction and affects the scale of the construction contract that the companies can bid for. If the total score is low, then the scale of the construction contract for public works decreases. Therefore, it is anticipated that the total score has a negative effect on exits.

(b) Model (2) consists of the X1, Y, and W scores, which are components of the total score. The $\mathrm{X} 2$ and $\mathrm{Z}$ scores also make up the total score. However, since the correlation among the $\mathrm{X} 1, \mathrm{X} 2$, and $\mathrm{Z}$ scores is very high, only the $\mathrm{X} 1$ score is considered for the multicollinearity problem.

The X1 score consists of the construction revenue and reflects the size of business. Hibiki et al. (2009) showed that SMEs with a low annual turnover are less likely to default. Shoko Research Institute (2012) also indicated that, in Japan, the smaller companies among the SMEs (which are not limited to the construction industry) are less likely to default. Therefore, it is anticipated that the X1 score has a positive effect on defaults. Conversely, Morikawa (1998) showed that the larger the business, the less likely the company would exit from the existing enterprise. Therefore, it is anticipated that the X1 score has a negative effect on exits. The Y score was designed by the Central Council on Construction Contracting Business, which revises Keisin as the index of default probability based on financial performance indicators (for details, see the Central Council on Construction Contracting (2007)). It is anticipated that the Y score has a negative effect on defaults. The W score shows the sociality of companies and evaluates the labour welfare situation and compliance of each company. It is costly for a company to obtain a high score with the W score. Since it would be a heavy burden on a company's financial condition, it would be difficult to invest in items of the $\mathrm{W}$ score. Therefore, it is anticipated that the $\mathrm{W}$ score will have a negative effect on defaults.

(c) Model (3) considers the financial performance indicators as the explanatory variables in 
computing the Keisin scores. Financial performance indicators consist of capital, earned surplus and debt turnover period. Capital (given in units of 1000 yen) and earned surplus (comprised of accumulated past profits and given in units of 100 million yen) reflect the size of the business. It is anticipated that capital and earned surplus have a positive effect on defaults and a negative effect on exits. The debt turnover period, which indicates the ratio of the total amount of current and fixed liabilities to the average monthly turnover, is the index of the resistance to debt so that when the value of the debt turnover period is larger, the ratios of the total amount of liabilities to average monthly turnover will be higher. Fujii and Takemoto (2010) found that increasing the debt ratio raises the default risk. Therefore, it is anticipated that the debt turnover period has a positive effect on defaults.

(d) Model (4) uses non-financial performance indicators as the explanatory variables. Nonfinancial performance consists of taking out unemployment insurance and operating years. It is costly to take out unemployment insurance and it would be a heavy burden on a company's financial condition. It is also a difficult task. Therefore, it is anticipated that taking out unemployment insurance has a negative effect on defaults. Kale and Arditi (1999) and Hibiki et al. (2009) indicated that companies in operation for fewer years are more likely to default. Therefore, it is anticipated that operating years has a negative effect on defaults. Similarly, Gibson and Harris (1996) showed that the exit probabilities of companies are high when their operating years are short. Therefore, it is anticipated that operating years has a negative effect on exits.

(e) Model (5) consists of the financial and non-financial performance indicators. The nonfinancial performance indicators are incorporated as an extension of Model (3). The concrete explanatory variables are capital, earned surplus, debt turnover period and operating years.

The same results are anticipated as in Models (3) and (4). It is anticipated that capital and 
earned surplus have a positive effect on defaults and a negative effect on exits; the debt turnover period has a positive effect on defaults, and operating years has a negative effect on defaults and exits.

\subsection{Findings}

This section considers the estimated results in Table 4.4. The findings for coefficients of each model are as follows.

(a) In Model (1), the coefficient of the total score is -0.00878 , which has a significant negative effect on exits. Therefore, companies with a low total score tend to exit from public works, which is consistent with the anticipation. The total score does not significantly affect defaults, which implies that the total score does not directly impact defaults.

(b) In Model (2), the coefficient of the X1 score is 0.00847 and that of the $\mathrm{Y}$ score is -0.00902 significantly on default. The coefficient of the $\mathrm{W}$ score is -0.00245 significantly on exit. It turns out that the higher the $\mathrm{X} 1$ score, the more likely the company will default. That is, this result implies that the smaller the construction revenue, the less likely the companies will default. Contrary to some intuitions, it is consistent with the anticipation following Hibiki et al. (2009) and Shoko Research Institute (2012). The reason why smaller companies are less likely to default is not exactly clear; however, the following points can be given as reasons. Small companies, such as family companies, may be able to restructure easily, but since it is more difficult for larger companies to restructure, larger companies among SMEs are more likely to default.

In addition, it turns out that the lower the $\mathrm{Y}$ score, the more likely the company will default. This represents that the Y score is well designed for predicting defaults, which is consistent with the anticipation. However, contrary to its anticipation, the $\mathrm{W}$ score does not have a significant effect on defaults. Finally, the $\mathrm{W}$ score has a negative effect on exits, which is consistent with the anticipation. 
(c) In Model (3), the coefficient of capital is 0.0000212 and that of debt turnover period is 0.247 significantly on default. The coefficient of capital is -0.0000749 and that of earned surplus is -1.51 significantly on exit.

Capital, which is an index that reflects business size, similar to Model (2), has a significant positive influence on defaults. This is consistent with the anticipation and Hibiki et al. (2009). Although the earned surplus reflecting the size is unable to find significant influence on defaults, the result that the default risk increases as the debt ratio (debt turnover period) increases agrees with the anticipation and Fujii and Takemoto (2010).

This result shows that companies with large amounts of capital and earned surplus are less likely to exit, which is consistent with the anticipation and Morikawa (1998).

(d) In Model (4), the coefficient of taking out unemployment insurance is -1.931 significantly on default. The coefficient of taking out unemployment insurance is -1.301 and that of years of operation is -0.0561 significantly on exit. This result shows that companies with unemployment insurance are less likely to default and it is possible to predict the influence on default by non-financial performance indicators. Contrary to Kale and Arditi (1999) and Hibiki et al. (2009), the present study is uable to find that companies in operation for fewer years are more likely to default. This result shows that companies with unemployment insurance are less likely to exit, while those that have been in operation for fewer years are more likely to exit. Regarding unemployment insurance, the results indicate that it is possible to predict the influence on exits by non-financial performance indicators. Regarding the years of operation, it is consistent with the anticipation and Morikawa (1998).

(e) In Model (5), the coefficient of capital is 0.0000263 and that of debt turnover period is 0.263 significantly on default. The coefficient of capital is -0.0000629 , that of earned surplus is -1.389 and that of operating years is -0.0351 significantly on exit. The sign of each variable' effect on exit and default corresponds to Models (4) and (5), which is 
consistent with the anticipation.

Next, the goodness of fit of the model is considered as follows. As shown in Table 4.4, Model (2) includes the lowest AIC, which consists of the X1, Y and W scores as the explanatory variables. As a result, the best goodness of fit of Models (2), (3) and (5) are also good AIC models. Model (2) performs successfully, and it is shown that continuation, default and exit are distinguished by the scoring. However, Model (1) does not have a substantial difference in goodness of fit from the other models and the total score is not significant for default. Therefore, this study cannot assess whether the combination of the weight of the Keisin score always affects defaults and exits significantly.

On the other hand, Model (4), which uses non-financial performance indicators, has the worst goodness of fit. However, by combining the non-financial indicators with the financial indicators (Model (5)), the value of AIC decreases, thus indicating that the goodness of fit of Model (5) is better. The goodness of fit for Pseudo $R^{2}$ is almost the same as that for AIC. 


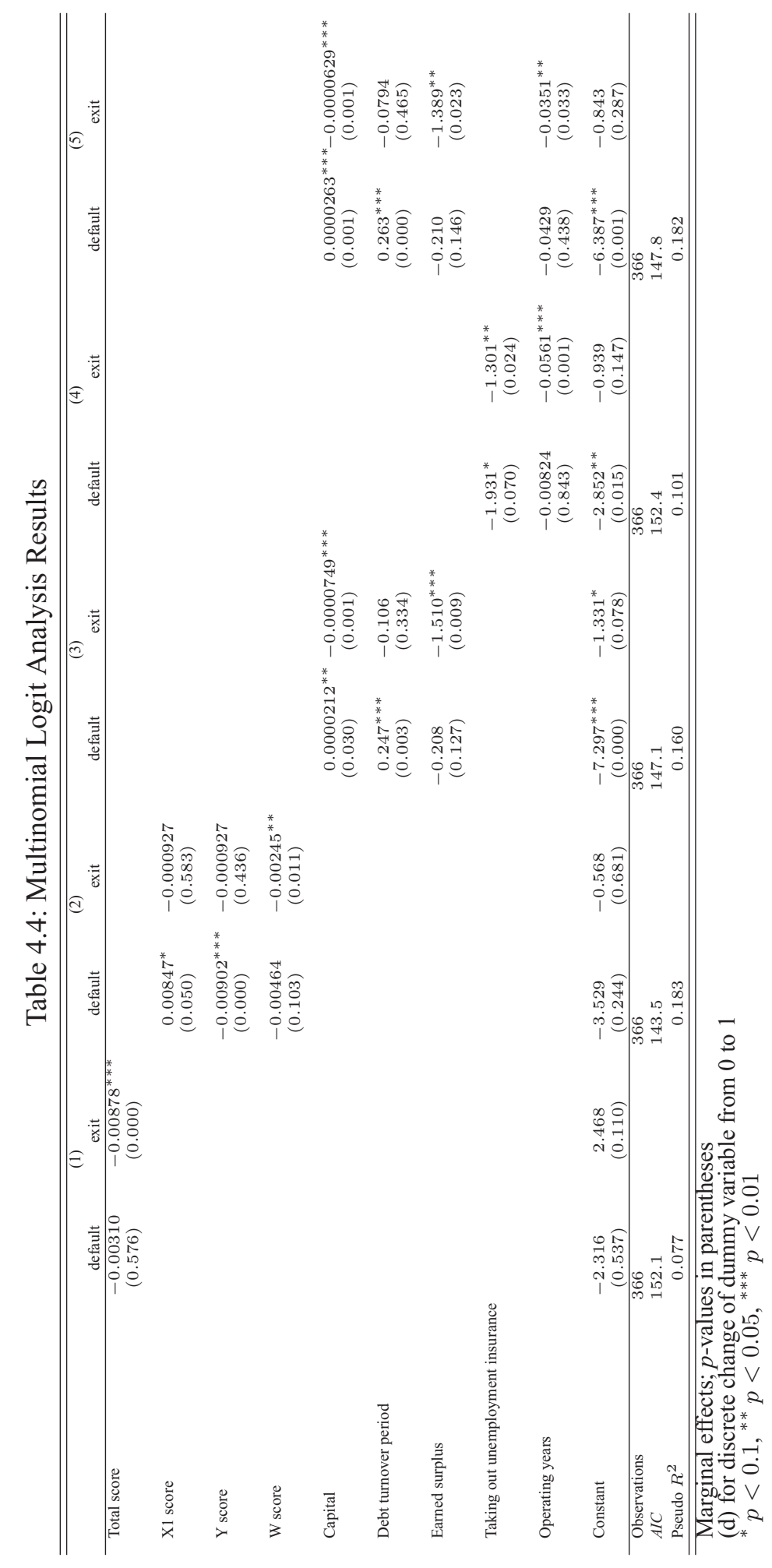




\subsection{Conclusion}

This study empirically analyses the factors that affect the defaults and exits of SMEs in the Japanese construction industry by using the multinomial logit model. The analysis results show that some Keisin scores and financial and non-financial performance indicators significantly affect defaults and exits. Especially, each Keisin score and the non-financial performance indicators can be used to predict the differences among exit, default and continuation companies.

In the study of Japanese SMEs beyond the construction industry, the definition of SMEs is ambiguous. There is limited analysis that employs the data and follows the definition of SMEs that strictly concern aspects such as the amount of capital and number of employees. Since the definition and observation of exit on SMEs are difficult, no study employs the statistical method for individual SMEs on exits. In additions, it is difficult to obtain SMEs data. In this study, these problems have been resolved by using the Keisin data. Moreover, since Keisin has established penalties for falsified applications, the data include only a few problems such as opacity of accounts. Therefore, this study accurately reflects the actual situation of SMEs in Japan.

The main limitations of the study are that the area is restricted to Japan, the data are obtained from a single fiscal year and there are low proportions of default (4/366) and exit (13/366) companies. Therefore, further study should focus on analysing data for several years since panel data would help determine how changes in the financial performance indicators of companies affect defaults and exits as well as increase sample size.

Finally, since the data are restricted to Japan, the result may not necessarily be the same for other countries. However, some results agree with existing foreign studies, which may be helpful for other countries. Furthermore, if the data in other countries are obtained, then the analytical method can be applied similarly. Other countries introducing such a system of objective evaluation on a unified standard would enable more detailed and reliable examinations of actual management conditions. For outside stakeholders, such as orderers of private works and financial institutions, the methods in this study may be helpful for evaluating SMEs. 


\section{Analysis of Japanese contractor's activity according to panel data}

\subsection{Introduction}

In Japan, having the evaluation of construction companies (Keiei Jikou Sinsa or Keisin in Japanese) is obligated for contractors to bid for public works projects. This study empirically analyzes the factors that affect company defaults and exits of public works projects using Keisin data and therefore analysis subject of this study is the companies that hope to participate to bid for public works projects.

This study analyzes the factors that influence defaults and exits using unbalanced panel data covering three years. This study uses the panel binary logit random effect model and performs parameter estimation using the maximum likelihood method for panel data. This study can thereby analyze the factors that affect defaults and exits for each explanatory variable while considering heterogeneity among companies.

This study defines defaulting (or bankrupt) companies as those that are unable to repay their debts and stop operating. This study defines exiting companies as those that stop operating as prime contractors for public works but otherwise stay in business by changing their business strategy. This study defines leaving companies as those that stop operating as prime contractor for public works. Leaving companies include both defaulting (or bankrupt) and exiting companies. This study defines continuing companies as those that stay in business as prime contractors for public works. For definitions of default and exit, see Figure 5.1. 


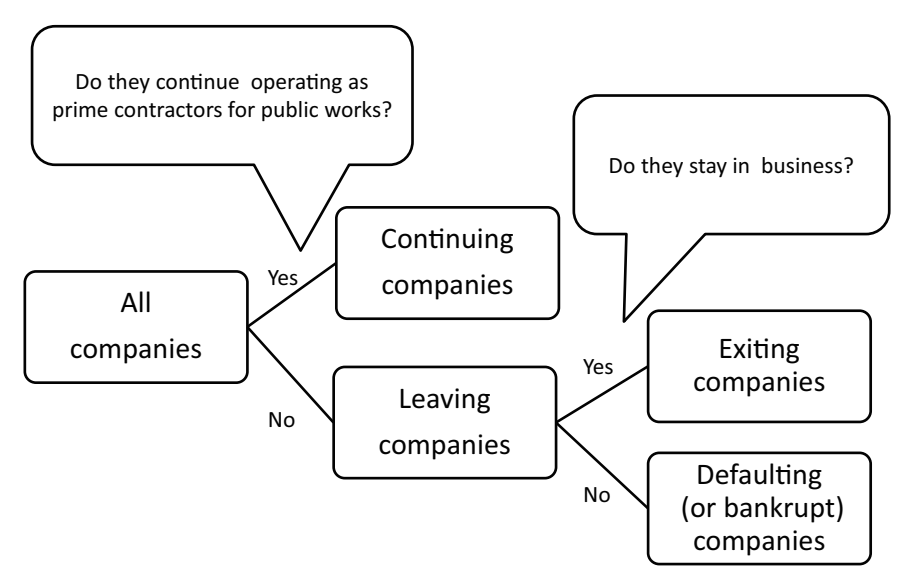

Figure 5.1: Definitions of default and exit

Studies in related areas focus only on default and bankruptcy. For example, studies of default such as Section 5.2.1, do not consider exiting companies that stop operating in a certain industry (or business model) but stay in business in another industry (or business model). Studies that examine leaving from the industry perspective, such as Section 5.2.2, focus on companies that leave an industry. They do not distinguish between exiting and defaulting companies but rather focus only on whether a certain industry (or business model) is abandoned. They have no interest in whether companies do or do not default.

This study distinguishes between defaults (bankruptcies) and exits and analyzes the factors that influence these two outcomes. This represents both the original contribution and the research objective of this study.

Also, there has been little empirical study globally on exits from business by small and medium-sized enterprises (SMEs), and thus, this study contributes to the field of the exit of SMEs.

\subsection{Literature Review}

This section reviews the typical studies on defaults and leavings. 


\subsubsection{Study of Default}

The most famous default risk measurement method using financial performance indicators is the Z score model introduced by Altman (1968). For the most classic example of using logit models in this field, Ohlson (1980) predicts default probability. Psillaki et al. (2010) show that nonfinancial performance indicators give useful prior information about the defaults of companies.

In the study of SMEs in Japan, Fujii and Takemoto (2010) develop a default risk evaluation model based on the large-scale data of financial performance indicators. They find that the cash equivalent / total assets ratio, the index of liquidity, and the margin / interest expense ratio, the index of responsibility, are significant explanatory variables. Hibiki et al. (2009) point out the usefulness of adding both the financial performance indicators and operating years to improve the scoring model for small business.

For the empirical analysis of defaults and default strategy in construction industry, Russell and Jaselskis (1992) develop discrete choice model to predict the probability of failure for contructors. They indicate that contract administrators can substantially reduce the probability of failure by increasing the amount of evaluation effort expended to evaluate contractors or the performance of cost monitoring during the construction phase. Russell and Zhai (1996) predict contractor failure examinating stochastic dynamics patterns, which includes percentage changes, trends, and volatility for economic and financial variables. Kale and Arditi (1999) analyze the defaults of contructors in the United States. They find an age-dependent default pattern where the risk of default increases initially with increasing company's age, reaches a peak point, and decreases after as companies grow older. Arditi, Koksal and Kale (2000) analyze the factors associated with contractor failures in the United States, and show that budgetary and macroeconomic issues are the main factors for contractor failures. They indicate that the contractors that take vigorous administrative measures to address budgeting issues and that react promptly to economic conditions by implementing appropriate strategic policies should be able to continue corporate activity. Kaplinski (2008) reveals the route of construction companies towards bankruptcy in Poland. Kaplinski (2008) mentions that Z-score index should be adjusted to eco- 
nomic conditions as country or industry, and bankruptcy results from poor financial standing of company. Dikmen, Talat Birgonul, Ozorhon and Egilmezer Sapci (2010) analyze the factors of business failure in Turkish construction industry using analytic network process model. Dikmen et al. (2010) indicate the importance of organisational and managerial factors, including the efficiency of the value chain at corporate level, the appropriateness of organisational decisions, and the availability of intangible resources for the survival. Lim, Oo and Ling (2010) examine the survival strategies from 34 interviews with senior executives of large and medium-sized companies in Singapore construction industry. Lim et al. (2010) show the importance of effective cost, risk, relationship and resource management. Mahamid (2012) analyzes what the factors affecting contractor's business failure using 44 factors in the West Bank in Palestine. Mahamid (2012) shows the factors as highly influential are human-related and the contractor's business failure arises from the financial factor than managerial and external factors. For study of default strategy, Al-Sobiei et al. (2005) predict the risk of contractor default in Saudi Arabia. They show that a strategy exists that could allow big construction owners to minimize the overall cost of contractor default. Holt (2013) comprehensively surveys the literature of construction business failure and synthesizes published knowledge to explore the causal agents of failure. Holt (2013) finds that generic failure agents are managerial, financial, company characteristics and macroeconomics.

As mensioned in Section 5.1, these studies concern bankruptcy rather than leavings. They do not consider the exit companies which are leaving but change their contents of business.

For the risk management studies in constrction, Akintoye and MacLeod (1997) decribe risk perception, organizational risk management, risk premium in construction projects, management of risk and current usage of risk management techniques on the basis of a survey of constractors and project management practices. Edwards and Bowen (1998) review and analyze the literature on construction and project risk management published during the period from 1960 to 1997 and discuss the soft systems issues as people problems of construction risk management. Tah and Carr (2000) show that the development of a common language for describing risks and remedial 
actions is important in order to build a better approach to construction risk management and propose the information model for the construction project risk management. For managing risks of international projects in Russia, Aleshin (2001) develops Risk Management Support System. Lyons and Skitmore (2004) provide the results of a survey of senior management in the Queensland engineering construction industry. Chiang and Cheng (2011) explore banks' perception on contractors' borrowing in Hong Kong and present findings on how banks have processed and evaluated contractors' loan applications. Lehtiranta (2013) reviews the studies on risk perceptions and approaches that published between 2000 and 2012.

These studies focus on risk management in constrction. Thus they do not analyze the factors that the default and the exit.

\subsubsection{Study of Leaving}

For the empirical analysis of leavings, Mansfield (1962) analyzes leavings from four industries in America, steel, petroleum, tires, and cars, using multiple regression analysis. Mansfield (1962) shows that as the rate of leavings decreases, the profitability or business size becomes larger. Moreover, Gibson and Harris (1996) use the binary logit model for manufacturing plants in New Zealand. They show that the leaving probabilities of companies become higher as the operating years grow shorter and the expense-to-sale ratio higher. Morikawa (1998) analyzes the companies with head offices in Tokyo using micro data from the Basic Survey of Business and Activity. The results show that the larger the size of a business, the less likely are the companies to leaving from existing enterprises.

For studies of leaving in construction industry, Chiang et al. (2001) examine the market structure of four different sectors: private building, public building, property development, and civil engineering in Hong Kong. They indicate that the lack of technological demand and supply has led to easy market entry and leave in the private building sector. Moreover, Oral and Mistikoglu (2007) examine the factors affecting the competition in Turkish brick industry. They describe the present condition that the Turkish brick industry is dominated by SMEs carrying out labour 
intensive production and indicate that barriers to entry and leave to national brick makers are low, as there are no government regulations.

As mentioned in Section 5.1, these studies focus on the leaving the construction industry from the standpoint of the industry organization. The definition of the leaving includes the default (bankruptcy) and the exit. Thus they do not distinguish between the default (bankruptcy) and the exit.

\subsection{Overview of Keisin}

This study empirically analyzes the factors that affect defaults and exits by using evaluations of construction companies (Keiei Jikou Sinsa or Keisin in Japanese). This section provides a brief explanation of Keisin. In order to contract public works projects, prime contractors must be assessed through the official construction company evaluation process. According to Japan's Construcion Business Act, this evaluation is conducted by the Ministry of Land, Infrastructure, Transport and Tourism (MLIT) or the prefecture governor. About $30 \%$ of the contractors in Japan have gone through Keisin. Using national unification objective standards for technology, management, and social responsibility, the Keisin system evaluates the capability of companies that contract public works. As shown in Table 5.1, the evaluated items consist of (1) business size (X1 and X2 scores), (2) business conditions (Y score), (3) technical strength ( $\mathrm{Z}$ score), and (4) other factors such as sociality (W score). They are evaluated through the assignment of scores.

The total score of each company is provided as the following weighted sum of the scores,

$$
\text { Total score }=0.25 \times \mathrm{X} 1+0.15 \times \mathrm{X} 2+0.2 \times \mathrm{Y}+0.25 \times \mathrm{Z}+0.15 \times \mathrm{W} \text {. }
$$

The total Keisin score is used to examine whether companies are qualified to enter competitive bids for public works projects. Regarding the qualification test, companies are rated using the Keisin score and their independent order assessment systems, such as past records of business 
Table 5.1: Keisin items

\begin{tabular}{cll}
\hline item & \multicolumn{1}{c}{ evaluation item } & score range \\
\hline $\mathrm{X} 1$ & Construction revenue (classified by industry) & $390 \sim 2268$ \\
\hline $\mathrm{X} 2$ & $\begin{array}{l}\text { Shareholders' equity } \\
\text { Average earnings }\end{array}$ & $454 \sim 2280$ \\
\hline $\mathrm{Y}$ & $\begin{array}{l}\text { Net paying interest / revenue } \\
\text { Debt turnover period } \\
\text { Ordinary income ratio } \\
\text { Gross profit / total capital } \\
\text { Net worth to fixed assets ratio } \\
\text { Capital to asset ratio }\end{array}$ & \\
Cash flow from operations (absolute cost) & $0 \sim 1595$ \\
\hline $\mathrm{E}$ Earned surplus (absolute cost) & $\begin{array}{l}\text { Number of technical staff (classified by industry) } \\
\text { Prime construction revenue (classified by industry) }\end{array}$ & $450 \sim 2366$ \\
\hline $\mathrm{W}$ & $\begin{array}{l}\text { The labor welfare situation } \\
\text { Conditions for continuing to operate in the construction industry } \\
\text { Contribution to a disaster-prevention activity } \\
\text { The compliance situation }\end{array}$ & \\
\hline & $\begin{array}{l}\text { The state of accounting in the construction industry } \\
\text { The research and development situation }\end{array}$ & $0 \sim 1750$ \\
\hline & & \\
\hline
\end{tabular}

contracts. This rating affects the companies' ability to obtain business contracts and the Keisin score therefore plays an important role.

The permission administrative agencies have established penal regulations such as the suspension of business for 30 days or more for falsified applications. Furthermore, when a punishment is imposed, any Keisin permission is revoked and the company is prohibited from obtaining further Keisin permission for five years. Therefore Keisin data is high reliability.

\subsection{Research Method}

\subsubsection{Estimation Method}

First, this study explain the estimation method of factor affecting default and continuation. This study sets $y_{i t+1}^{D}$ as binary variable which expressres default (1) or continuation (0) of comany $i$ at time $t+1$. Furthermore, this study set $\boldsymbol{x}_{i t}$ as explanatory variables vector of comany $i$ at time $t$. Because the explained variable $y_{i t+1}^{D}$ is binary variable and the data is panel data, the panel logit model is suitable model to examine how the explanatory variables affect default. Furthermore, in order to analyze the explanatory variables that affect defaults after controlling for heterogeneity among companies, this study chooses the panel binary logit random effect model. 
This study explain the panel logit random effect model briefly. Refer to Wooldridge (2013, Chapter 15) for the detail of panel binary logit random effect model. For the company $i=$ $1,2, \ldots, N$ and time $t=1,2, \ldots, T$, this study assume that

$$
P\left(y_{i t+1}^{D}=1 \mid \boldsymbol{\beta}, \boldsymbol{\alpha}_{i}, \boldsymbol{x}_{i t}\right)=\Lambda\left(\alpha_{i}+\boldsymbol{x}_{i t}^{\prime} \boldsymbol{\beta}\right)
$$

where $\Lambda(u)=\frac{e^{u}}{1+e^{u}}$ is a logistic fuction and $\alpha_{i}$ is an individual effect and that $\alpha_{i} \sim N\left(0, \sigma_{\alpha}^{2}\right)$ and there is no correlation between $\alpha_{i}$ and $\boldsymbol{x}_{i t}$. Then the joint density of $i$ th observations as follows,

$f\left(y_{i 2}^{D}, y_{i 3}^{D}, \ldots, y_{i T+1}^{D}\right)=\int_{-\infty}^{\infty}\left[\prod_{t=1}^{T} \Lambda\left(\alpha_{i}+\boldsymbol{x}_{i t}^{\prime} \boldsymbol{\beta}\right)^{y_{i t+1}}\left\{1-\Lambda\left(\alpha_{i}+\boldsymbol{x}_{i t}^{\prime} \boldsymbol{\beta}\right)\right\}^{1-y_{i t+1}}\right] g\left(\alpha_{i} \mid \sigma_{\alpha}^{2}\right) d \alpha_{i}$,

where $g\left(\alpha_{i} \mid \sigma_{\alpha}\right)$ is the probability density function of $\alpha_{i}$

$$
g\left(\alpha_{i} \mid \sigma\right)=\frac{1}{\sigma_{\alpha} \sqrt{2 \pi}} \exp \left(-\frac{\alpha_{i}^{2}}{2 \sigma_{\alpha}^{2}}\right)
$$

The log likelihood of all data is as

$$
\begin{aligned}
& \ln L\left(\boldsymbol{\alpha}, \boldsymbol{\beta}, \sigma_{\alpha}\right)= \\
& \quad \sum_{i=1}^{N} \ln \int_{-\infty}^{\infty}\left[\prod_{t=1}^{T} \Lambda\left(\alpha_{i}+\boldsymbol{x}_{i t}^{\prime} \boldsymbol{\beta}\right)^{y_{i t+1}}\left\{1-\Lambda\left(\alpha_{i}+\boldsymbol{x}_{i t}^{\prime} \boldsymbol{\beta}\right)^{1-y_{i t+1}}\right\}\right] g\left(\alpha_{i} \mid \sigma_{\alpha}^{2}\right) d \alpha_{i} .
\end{aligned}
$$

The parameters $\boldsymbol{\alpha}, \boldsymbol{\beta}, \sigma_{\alpha}$ are estimated as maximum the Equation (5.5), this estimation method is called the maximum likelihood estimation.

This study sets $y_{i t+1}^{E}$ as binary variable express exit or continuation of comany $i$ at time $t+1$. Replacing $y_{i t+1}^{D}$ to $y_{i t+1}^{E}$, this study examine the factors affecting exit and continuation in the same way as default case. 


\subsubsection{Goodness of Fit}

In order to compare each model's goodness of fit, this study uses Akaike Information Criteria (AIC) as follows,

$$
A I C=-2 \ln L+2 k
$$

where $\ln L$ is the maximized value of $\log$ likelihood and $k$ is the number of parameters in model. A model with the minimum AIC value is preferred. Refer to (Winkelmann and Boes, 2009, chapter 3) for the details of AIC.

\subsection{Data and Variables}

The source of this data is Keisin Trend $5^{1}$, Keisin's database. This study analyzes companies headquartered in Setagaya Ward, Tokyo Prefecture that must obtain permission from the MILT or prefecture governor and that have applied for Keisin. According to section 1 of article 2 of the Small and Medium-sized Enterprise Basic $\mathrm{Act}^{2}$, small and medium-sized construction enterprises are defined as those with capital of 300 million yen or less, or 300 or fewer regular employees. Because it is impossible to obtain the number of regular employees, This study focuses on companies that have capital of 300 million yen or less in this empirical analysis.

This study classifies the companies that applied for Keisin in 2008-2010 into the following three categories. The companies that also applied for Keisin in the following fiscal year are continuing companies. The companies that did not apply for Keisin in the following fiscal year and were forced to stop operating or went bankrupt are defaulting companies. The remainder are exiting companies. Moreover, this study uses the explanatory variables in 2007-2009. this study excludes companies with missing variables from this analysis. Analyzing the data during

\footnotetext{
${ }^{1}$ http: //www.wise.co.jp/trend-web/

${ }^{2}$ Small and Medium-sized Enterprise Basic Act was enforced in 1963. The purpose of this Law is to promote in a comprehensive manner measures for SMEs by establishing the basic principles, basic policies and other basic matters relating to measures for SMEs and clarifying the responsibilities of the State and of local public entities.
} 
the period, the influence of the Subprime mortgage crisis on default and exit can be examined. Because the revision of Keisin was done in 2007, it is difficult to use the keisin data before 2007 and after 2007 simultaneously to examine the influence.

The explanatory variables of each model are as follows.

(a) Model (1) employs the total Keisin score as the explanatory variable.

(b) Model (2) employs the X1, Y, and W scores, which are the components of the total score. In fact, the $\mathrm{X} 2$ and $\mathrm{Z}$ scores also make up the total score. However, since the correlations among the $\mathrm{X} 1, \mathrm{X} 2$, and $\mathrm{Z}$ scores is very high, only the $\mathrm{X} 1$ score is considered due to the problem of multicollinearity.

(c) Model (3) consists of the financial and non-financial performance indicators.

We explain the non-statutory worker's compensation system as a non-financial performance indicator. There are two types of worker's accident compensation system in Japan: statutory worker's compensation system and non-statutory worker's compensation system. The nonstatutory worker's compensation system is supplementary insurance to statutory worker's compensation system. Because the insurance fee of non-statutory worker's compensation system is paid by each insured company, taking out non-statutory worker's compensation system are burden for contractors.

The fundamental statistics for each variable are given in Table $5.2^{3}$. Using unbalanced panel data covering three years, the final consisnts of 1022 observations for 391 companies (including eight defaulting and 37 exiting companies).

\footnotetext{
${ }^{3}$ The units for variables are as follows. Capital is in thousands of yen; net paying interest / revenue and gross profit / total capital are in percentages; retirement allowances or company pension and non-statutory worker's compensation system take values of 0 (not taking out) or 1 (taking out); and years in operation in years.
} 
Table 5.2: Fundamental statistics

\begin{tabular}{|c|c|c|c|c|c|}
\hline Variable & Sample size & Mean & Std. Dev. & Min & $\operatorname{Max}$ \\
\hline Total score & 1022 & 715.181 & 131.6064 & 344 & 1205 \\
\hline X1 score & 1022 & 767.9276 & 164.5564 & 414 & 1431 \\
\hline Y score & 1022 & 736.7916 & 203.5648 & 0 & 1147 \\
\hline W score & 1022 & 723.8748 & 379.2162 & 0 & 1320 \\
\hline Net paying interest / revenue & 1022 & .66030721 & .9810757 & -.3 & 5.1 \\
\hline Gross profit to net sales ratio & 1022 & .2531905 & .1493955 & -.1099444 & 1.412632 \\
\hline Capital & 1022 & 24628.59 & 25772.7 & 0 & 250000 \\
\hline Gross profit / total capital & 1022 & 34.05576 & 19.10848 & 6.5 & 63.6 \\
\hline Years in operation & 1022 & 29.92172 & 14.60548 & 0 & 60 \\
\hline Taking out retirement allowances or company pension & 1022 & .5665362 & .4957958 & 0 & 1 \\
\hline Taking out non-statutory worker's compensation system & 1022 & .56066542 & .4965491 & 0 & 1 \\
\hline
\end{tabular}

\subsection{Results and Interpretation}

\subsubsection{Results}

This study will now present a summary of the analysis results. Table 5.3 shows the estimation result for default and Table 5.4 shows the estimation result for exit of model (1)-(3), respectively.

Table 5.3 shows that $\mathrm{Y}$ score and $\mathrm{W}$ score negative significantly affect default and X1 score positive significantly affect default. As already mentioned, Y score represents business condition, $\mathrm{W}$ score represents other factors such as sociality and $\mathrm{X} 1$ score represents business size. That is, the companies with bad business condition, the companies with low sociality and the companies with relatively large business size in SMEs tend to default. Table 5.3 also shows capital and net paying interest / revenue positive significantly affect default and gross profit to net sales ratio and taking out retirement allowances or company pension negative significantly affect default. In other words, the companies with relatively large business size in SMEs, the companies with small financial debt ratio, the companies with large profit ratio and the companies without preparing retirement allowances or company pension tend to default.

Table 5.4 shows that total score and $\mathrm{W}$ score negative significantly affect exit. That is, the companies with low total score and the companies with low sociality tend to exit. Table 5.4 also shows that capital, gross profit / total capital, years in operation and taking out non-statutory worker's compensation system negative significantly exit. In other words, the companies with 
Table 5.3: Analysis results for defaults

\begin{tabular}{|c|c|c|}
\hline$\overline{(1)}$ & (2) & (3) \\
\hline $\begin{array}{c}-0.00276 \\
(0.499)\end{array}$ & & \\
\hline X1 score & $\begin{array}{l}0.00654^{* *} \\
(0.043)\end{array}$ & \\
\hline Y score & $\begin{array}{c}-0.00714^{\text {*** }} \\
(0.005)\end{array}$ & \\
\hline W score & $\begin{array}{c}-0.00235^{*} \\
(0.075)\end{array}$ & \\
\hline Capital & & $\begin{array}{l}0.0000221^{* *} \\
(0.036)\end{array}$ \\
\hline Net paying interest / revenue & & $\begin{array}{l}0.994^{* * *} \\
(0.002)\end{array}$ \\
\hline Gross profit to net sales ratio & & $\begin{array}{r}-8.018^{*} \\
(0.077)\end{array}$ \\
\hline Taking out retirement allowances or company pension & & $\begin{array}{r}-2.604^{*} \\
(0.053)\end{array}$ \\
\hline Observations & 1022 & 1022 \\
\hline 98.8 & 84.1 & 87.2 \\
\hline
\end{tabular}

Marginal effects; $p$-values in parentheses

${ }^{*} p<0.1,{ }^{* *} p<0.05,{ }^{* * *} p<0.01$ 
Table 5.4: Analysis results for exits

\begin{tabular}{|c|c|c|}
\hline (1) & (2) & (3) \\
\hline $\begin{array}{c}-0.0111^{* * *} \\
(0.005)\end{array}$ & & \\
\hline X1 score & $\begin{array}{l}0.000296 \\
(0.902)\end{array}$ & \\
\hline Y score & $\begin{array}{c}-0.000556 \\
(0.610)\end{array}$ & \\
\hline W score & $\begin{array}{c}-0.00406^{* * *} \\
(0.001)\end{array}$ & \\
\hline Capital & & $\begin{array}{l}-0.0000604^{* *} \\
(0.033)\end{array}$ \\
\hline Gross profit / total capital & & $\begin{array}{c}-0.0264^{*} \\
(0.087)\end{array}$ \\
\hline Years in operation & & $\begin{array}{c}-0.0855^{* *} \\
(0.010)\end{array}$ \\
\hline Taking out non-statutory worker's compensation system & & $\begin{array}{l}-1.615^{* * *} \\
(0.007)\end{array}$ \\
\hline Observations & 1022 & 1022 \\
\hline 294.8 & 288.2 & 278.5 \\
\hline
\end{tabular}

Marginal effects; $p$-values in parentheses

${ }^{*} p<0.1,{ }^{* *} p<0.05,{ }^{* * *} p<0.01$ 
relatively small business size in SMEs, the companies with small profit ratio, the companies with short operating years and the companies without non-statutory worker's compensation system tend to default.

These results indicate that both financial and non-financial performance indicators affect defaults and exits by companies.

The goodness of fit of the model is determined by comparing the numerical value of the AIC. In the case of defaults, as shown in Table 5.3, model (2) has the lowest AIC, which consists of each of the $\mathrm{X} 1, \mathrm{Y}$, and $\mathrm{W}$ scores as the explanatory variables, and it is shown that the scoring is able to distingish between continuing and defaulting companies. In the case of exits, as shown in Table 5.4, the best goodness of fit is achieved by model (3) by combining the non-financial and financial indicators.

\subsubsection{Interpretation}

Consequently, this study shows that the characteristics of defaulting and exiting companies are different and discuss the reasons for this.

In the case of financial indicators, net paying interest / revenue affects defaults. When companies are not able to pay their debts, a default is considered to have occurred. Therefore financial debt ratios such as net paying interest / revenue are relevant to defaults.

Moreover, capital have a positive relationship with defaults. Since capital is reflected in business size, smaller companies are less likely to default. The reason is as follows. Ogi, Toshiro and Hibiki (2014a) point out that since the most of small sized firms are run by owner's family members, and deficits incurred from their businesses are compensated with the private assets of the family, which are not described in the companies' financial statements. Furthermore, Ogi, Toshiro and Hibiki (2014b) show that small companies whose owner's private assets are larger tend to non-default.

This study provides an additional explanation for this phenomenon using other data. Figure 5.2 shows default probabilities of companies in the construction industry and all industries 
by size of capital ${ }^{4}$. From Figure 5.2, the default probabilities of the large-scale companies with the capital of one billion yen or mode and those of the small-scale companies with the capital of less than 10 million yen are low. On the other hand, the default probabilities of the medium-scale companies are high. It is true not only in the construction industry but also in all industry. In particular, default probabilities of companies with the capital of 50 million or more, less than 100 million yen are high in the construction industry. As previously stated, this study focuses only the companies with capital of 300 million yen or less. Therefore, as compared with SMEs, in that except for large companies, the default probabilities of relatively large companies in SMEs are high.

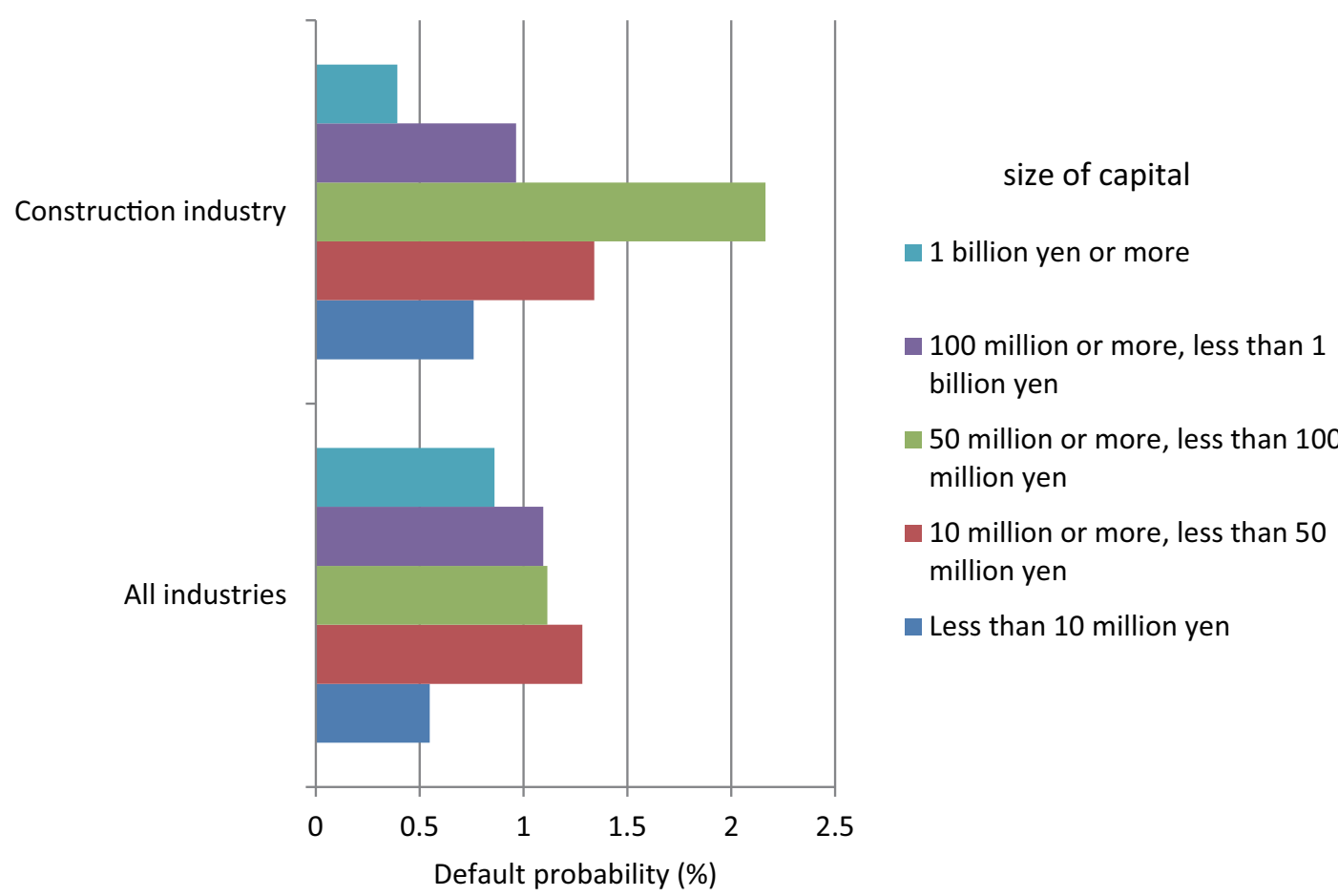

Figure 5.2: Default probability by size of capital

\footnotetext{
${ }^{4}$ The number of companies is obtained from the Economic Census for Business Frame in 2009 by Ministry of Economy, Trade and Industry. The number of default is obtained from Annual business failure investigation report by Business Mutual Aid Association in Japan.
} 
In contract, financial debt ratios do not have a significant effect on exiting, and compaies with low capital and those that have been operating for fewer years tend to exit. Because of this, this study considers that younger companies with low capital tend not to participate in bids for public works and prefer to serve as subcontractors for public works or in the private sector. Prime contractors should have equipment and human capital such as construction machines and engineers, among others, but it may be difficult for young companies and companies with less capital to obtain these types of resources.

The profit ratio (gross profit to net sales ratio or gross profit / total capital) became small, it is easy to exit and default. It is suggested that companies with high profit ratios are able to continue operating without having to default or exit.

With regard to the Keisin score, the total score does not significantly affect defaults and companies with low total scores are more likely to exit. This implies that Keisin scores do not directly impact defaults, but the total score is the most important factor in bidding for public works. Therefore, companies with low total scores are at a disadvantage in bids for public work and tend to exit this line of business.

In relation to the non-financial performance indicators, taking out retirement allowances or company pensions affect defaults and taking out non-statutory worker's compensation system affect exits. Retirement allowances or company pensions serve to guarantee retirement for employees and the decision of whether to pay the additional cost is easily influenced by financial conditions. On the other hand, the provision of non-statutory worker's compensation system is compulsory for the contracting of public works, and is easily influenced by either exiting or continuing in the public works business. Therefore, the nature of both types of insurance explains the differences between defaulting and exiting companies. 


\subsection{Conclusion}

This study empirically analyzes the factors that affect defaults and exits of public works projects on SMEs using the panel binary logit random effect model in Japanese construction industry. This study is focuses on exiting companies as well as defaulting companies. Therefore, this study distinguishes between defaults (bankruptcies) and exits and analyzes the factors that influence these two outcomes. This represents both the original contribution and the research objective of this study.

The study shows defaulting and exiting companies have different characteristics by using Keisin data. The result shows financial indicators, non-financial indicators, and Keisin scores significantly affect default and exit. Especially, the result that non-financial performance such as taking out insurances (retirement allowances or company pension and non-statutory worker's compensation system) explains the differences between defaulting and exiting companies is novel. From the point of view of workers' lifelong protection, it shows that the companies where the labor welfare situation is substantial are less likely to default and exit. It indicates that the need for evaluations of construction companies by the non-financial performance indicators as the labor welfare situation.

Although the Keisin data are used only to determine whether companies are qualified to enter bids for public works projects, it is possible to apply them to the attribution analysis of the default and exit of companies.

In the study of Japanese SMEs beyond the construction industry, the definition of SMEs is ambiguous. Few analyses are based on data and strictly follow the definition of SMEs with regard to matters such as the amount of capital and number of employees. There are no studies that use statistical methods to examine exiting or leaving among SMEs in Japan. Following the definition of SMEs, this study select only companies with capital of 300 million yen or less. Since Keisin penalties have been established to deter falsified applications, this data are highly reliable. Therefore, the construction company evaluation data have few problems, such as opacity of accounts. Accordingly, this study accurately reflects actual conditions of Japanese 
SMEs. Hence, this study contributes to the fields of risk and corporate activity (defaults and exits) as they pertain to SMEs.

However, the scope of this study was restricted to the construction industry and the Setagaya Ward, Tokyo Prefecture. A direction for future studies would be to extend the analysis to other industries and areas, which would allow for the more comprehensive determination of the factors that affect defaults and exits of SMEs. 


\section{Bibliography}

Abidali, A. F. and F. Harris (1995) "A methodology for predicting company failure in the construction industry," Construction Management and Economics, Vol. 13, No. 3, pp. 189-196.

Akintoye, A. S. and M. J. MacLeod (1997) "Risk analysis and management in construction," International Journal of Project Management, Vol. 15, No. 1, pp. 31-38.

Al-Sobiei, O. S., D. Arditi, and G. Polat (2005) "Predicting the risk of contractor default in Saudi Arabia utilizing artificial neural network (ANN) and genetic algorithm (GA) techniques," Construction Management and Economics, Vol. 23, No. 4, pp. 423-430.

Aleshin, A. (2001) "Risk management of international projects in Russia," International Journal of Project Management, Vol. 19, No. 4, pp. 207-222.

Altman, E. I. (1968) "Financial ratios, discriminant analysis and the prediction of corporate bankruptcy," Journal of Finance, Vol. 23, No. 4, pp. 589-609.

Arditi, D., A. Koksal, and S. Kale (2000) "Business failures in the construction industry," Engineering Construction and Architectural Management, Vol. 7, No. 2, pp. 120-132.

Cameron, A. C. and P. K. Trivedi (2005) Microeconometrics: methods and applications: Cambridge University Press.

Caves, R. E. and M. E. Porter (1976) "Barriers to exit," in Qualls, D. P. and Masson, R., eds., Essays on Industrial Organization in Honor of Joe S. Bain, Ballinger: Cambridge, MA, pp. 36-69. 
Central Council on Construction Contracting (2007) "Expert Committee on the Revision of Keiei Jikou Sinsa, General Meeting, 3rd document," Ministry of Land, Infrastructure, Transport and Tourism [in Japanese].

Central Council on Construction Contracting (2007) "Third Expert Committee on the Revision of Keiei Jikou Sinsa, 4th document," Ministry of Land, Infrastructure, Transport and Tourism [in Japanese].

Chiang, Y. H. and E. W. Cheng (2011) "Revealing bank lending decisions for contractors in Hong Kong,” International Journal of Project Management, Vol. 29, No. 2, pp. 137-145.

Chiang, Y. H., B. S. Tang, and W. Y. Leung (2001) "Market structure of the construction industry in Hong Kong," Construction Management and Economics, Vol. 19, No. 7, pp. 675-687.

Dikmen, I., M. Talat Birgonul, B. Ozorhon, and N. Egilmezer Sapci (2010) "Using analytic network process to assess business failure risks of construction firms," Engineering, Construction and Architectural Management, Vol. 17, No. 4, pp. 369-386.

Edwards, P. J. and P. A. Bowen (1998) "Risk and risk management in construction: a review and future directions for research," Engineering Construction and Architectural Management, Vol. 5, No. 4, pp. 339-349.

Fujii, M. and R. Takemoto (2010) "Term structure of default risk: An empirical analysis of Japanese SMEs," FSA Research Review, Vol. 6, pp. 242-268, [in Japanese].

Gibson, J. K. and R. I. D. Harris (1996) "Trade liberalisation and plant exit in New Zealand manufacturing," Review of Economics and Statistics, Vol. 78, No. 3, pp. 521-529.

Hall, G. (1994) "Factors distinguishing survivors from failures amongst small firms in the UK construction sector," Journal of Management Studies, Vol. 31, No. 5, pp. 737-760.

Hibiki, N., K. Ogi, and M. Toshiro (2009) "Significant of operating year on the credit scoring model for small companies," JAFEE Journal, pp. 83-116, [in Japanese]. 
Holt, G. D. (2013) “Construction business failure: conceptual synthesis of causal agents," Construction Innovation, Vol. 13, No. 1, pp. 50-76.

Huang, Y. L. (2009) "Prediction of contractor default probability using structural models of credit risk: an empirical investigation," Construction Management and Economics, Vol. 27, No. 6, pp. 581-596.

Investigative Commission of Support Measures for Preservation of Debt to Subcontractors (2010) "Introduction of New Support Measures for Preservation of Debt to Subcontractors," Ministry of Land, Infrastructure, Transport and Tourism, [in Japanese].

Japan Federation of Construction Contractors (2012) Handbook of Construction: Japan Federation of Construction Contractors, [in Japanese].

Kale, S. and D. Arditi (1999) “Age-dependent business failures in the US construction industry," Construction Management and Economics, Vol. 17, No. 4, pp. 493-503.

Kanto Regional Development Bureau, Ministry of Land, Infrastructure, Transport and Tourism (2012) “Guidance of submissions for management scale and claim for total score," Ministry of Land, Infrastructure, Transport and Tourism, [in Japanese].

Kaplinski, O. (2008) "Usefulness and credibility of scoring methods in construction industry," Journal of Civil Engineering and Management, Vol. 14, No. 1, pp. 21-28.

Ministry of Land, T., Infrastructure and Tourism (2012) "Survey on the Construction Industry Structure in Fiscal 2011," Ministry of Land, Infrastructure, Transport and Tourism [in Japanese].

Lehtiranta, L. (2013) "Risk perceptions and approaches in multi-organizations: A research review 2000-2012," International Journal of Project Management, in press.

Leland, H. E. and K. B. Toft (1996) “Optimal capital structure, endogenous bankruptcy, and the term structure of credit spreads," Journal of Finance, Vol. 51, No. 3, pp. 987-1019. 
Lim, B. T. H., B. L. Oo, and F. Ling (2010) "The survival strategies of singapore contractors in prolonged recession," Engineering, Construction and Architectural Management, Vol. 17, No. 4, pp. 387-403.

Lyons, T. and M. Skitmore (2004) "Project risk management in the Queensland engineering construction industry: a survey," International Journal of Project Management, Vol. 22, No. 1, pp. 51-61.

Mahamid, I. (2012) "Factors affecting contractor's business failure: contractors' perspective," Engineering, Construction and Architectural Management, Vol. 19, No. 3, pp. 269-285.

Mansfield, E. (1962) "Entry, Gibrat's law, innovation, and the growth of firms," American Economic Review, Vol. 52, No. 5, pp. 1031-51.

Morikawa, M. (1998) "Entry into new businesses and exit from existing businesses: An empirical analysis of the Japanese firm," \#98-DOJ-87, the Research Institute of International Trade and Industry [in Japanese].

Ogi, K., M. Toshiro, and N. Hibiki (2014a) "Effect of firm age in credit scoring model for small sized firms," Proceedings of the Asia Pacific Industrial Engineering \& Management Systems Conference.

Ogi, K., M. Toshiro, and N. Hibiki (2014b) "The robustness of firm age and the relationship between firm age and private assets on the credit scoring model for small companies," Proceedings of 41th JAFEE meeting, [in Japanese].

Ohlson, J. A. (1980) "Financial ratios and the probabilistic prediction of bankruptcy," Journal of Accounting Research, Vol. 18, No. 1, pp. 109-131.

Omura, K., S. Mizukami, M. Kusumi, and Y. Shiogai (2002) “The financial features of defaulting companies and the lending behavior of financial institutions," Director General for Economic Assessment and Policy Analysis Discussion Paper, DP/02-5, Cabinet Office [in Japanese]. 
Oral, E. L. and G. Mistikoglu (2007) "Competitive analysis of the Turkish brick industry-a case study for developing countries," Building and Environment, Vol. 42, No. 1, pp. 416-423.

Porter, M. E. (1980) Competitive Strategy: The Free Press.

Psillaki, M., I. E. Tsolas, and D. Margaritis (2010) "Evaluation of credit risk based on firm performance," European Journal of Operational Research, Vol. 201, No. 3, pp. 873-881.

Russell, J. S. and E. J. Jaselskis (1992) "Predicting construction contractor failure prior to contract award," Journal of Construction Engineering and Management, Vol. 118, No. 4, pp. $791-811$.

Russell, J. S. and H. Zhai (1996) "Predicting contractor failure using stochastic dynamics of economic and financial variables," Journal of Construction Engineering and Management, Vol. 122, No. 2, pp. 183-191.

Sakano, T. (2008) "The bid action and the percentage of victories under the minimum restriction price," Japan Society of Civil Engineers special priority subject report(in Japanese), pp. 115118.

Shoko Research Institute (2012) "Bankruptcy and financial condition of SMEs," Shoko Research Institute [in Japanese].

Small and Medium Enterprise Agency eds. (2012) 2012 White Paper on Small and Medium Enterprises in Japan: Nikkei Printing, [in Japanese].

Tah, J. H. M. and V. Carr (2000) "Information modelling for a construction project risk management system," Engineering Construction and Architectural Management, Vol. 7, No. 2, pp. 107-119.

Takahashi, N. (2001) "Changes to accounting regulations and the grading system in the japanese construction industry," Sapporo University Women's Junior College Journal, Vol. 38, pp. 87119, [in Japanese]. 
Tanno, T., T. Yokota, T. Uno, and M. Kato (2008) "Fact-finding survey and economic analysis on cartels," CR 03-07 CPRC Research Report (in Japanese).

Winkelmann, R. and S. Boes (2009) Analysis of Microdata: Springer, 2nd edition.

Wooldridge, J. M. (2013) Introductory econometrics: a modern approach: South-Western, 5th edition.

Yoshimori, I. (2006) "A basic research on accounting for the construction industry's based on the business evaluation system and the tax code," Ph.D. dissertation, Kyushu University, [in Japanese]. 